\title{
Article \\ An Investigation towards Coupling Molecular Dynamics with Computational Fluid Dynamics for Modelling Polymer Pyrolysis
}

\author{
Timothy Bo Yuan Chen ${ }^{1}\left(\mathbb{D}\right.$, Ivan Miguel De Cachinho Cordeiro ${ }^{1}$, Anthony Chun Yin Yuen ${ }^{1, *(\mathbb{D} \text {, }}$ \\ Wei Yang ${ }^{2}{ }^{(}$, , Qing Nian Chan ${ }^{1}$, Jin Zhang ${ }^{1}{ }^{(}$, Sherman C. P. Cheung ${ }^{3}\left(\mathbb{D}\right.$ and Guan Heng Yeoh ${ }^{1,4}$
}

\section{check for}

updates

Citation: Chen, T.B.Y.; De Cachinho Cordeiro, I.M.; Yuen, A.C.Y.; Yang, W.; Chan, Q.N.; Zhang, J.; Cheung, S.C.P.; Yeoh, G.H. An Investigation towards Coupling Molecular

Dynamics with Computational Fluid Dynamics for Modelling Polymer Pyrolysis. Molecules 2022, 27, 292. https://doi.org/10.3390/ molecules 27010292

Academic Editor: Giuseppe Cirillo

Received: 30 July 2021

Accepted: 27 December 2021

Published: 4 January 2022

Publisher's Note: MDPI stays neutral with regard to jurisdictional claims in published maps and institutional affiliations.

Copyright: (C) 2022 by the authors. Licensee MDPI, Basel, Switzerland. This article is an open access article distributed under the terms and conditions of the Creative Commons Attribution (CC BY) license (https:// creativecommons.org/licenses/by/ $4.0 /)$.
1 School of Mechanical and Manufacturing Engineering, University of New South Wales, Sydney, NSW 2052, Australia; timothy.chen@unsw.edu.au (T.B.Y.C.); i.decachinhocordeiro@unsw.edu.au (I.M.D.C.C.); qing.chan@unsw.edu.au (Q.N.C.); jin.zhang6@unsw.edu.au (J.Z.); g.yeoh@unsw.edu.au (G.H.Y.)

2 School of Energy, Materials and Chemical Engineering, Hefei University, 99 Jinxiu Avenue, Hefei 230601, China; yangwei@hfuu.edu.cn

3 School of Aerospace, Mechanical and Manufacturing Engineering, RMIT University, Melbourne, VIC 3083, Australia; chipok.cheung@rmit.edu.au

4 Australian Nuclear Science and Technology Organization (ANSTO), Locked Bag 2001, Kirrawee DC, NSW 2232, Australia

* Correspondence: c.y.yuen@unsw.edu.au

\begin{abstract}
Building polymers implemented into building panels and exterior façades have been determined as the major contributor to severe fire incidents, including the 2017 Grenfell Tower fire incident. To gain a deeper understanding of the pyrolysis process of these polymer composites, this work proposes a multi-scale modelling framework comprising of applying the kinetics parameters and detailed pyrolysis gas volatiles (parent combustion fuel and key precursor species) extracted from Molecular Dynamics models to a macro-scale Computational Fluid Dynamics fire model. The modelling framework was tested for pure and flame-retardant polyethylene systems. Based on the modelling results, the chemical distribution of the fully decomposed chemical compounds was realised for the selected polymers. Subsequently, the identified gas volatiles from solid to gas phases were applied as the parent fuel in the detailed chemical kinetics combustion model for enhanced predictions of toxic gas, charring, and smoke particulate predictions. The results demonstrate the potential application of the developed model in the simulation of different polymer materials without substantial prior knowledge of the thermal degradation properties from costly experiments.
\end{abstract}

Keywords: combustion; computational fluid dynamics; detailed chemistry; flame retardants; molecular dynamics; pyrolysis

\section{Introduction}

Fire risks associated with lightweight building materials have continuously threatened building occupants, the environment, and properties [1,2]. The rise in material complexity has also generated new challenges and requirements concerning fire safety protection systems. Subsequently, it has driven significant interest in developing robust numerical tools to effectively assess the fire behaviours and performance of these combustible materials in fire investigation studies and establish safe use guidelines, especially for the rapid development of flame retardants, prediction of toxicity emissions and self-extinguishing behaviours.

The application of Computational Fluid Dynamic (CFD) modelling on building fires has gained massive adoption due to the rapid advancement of computational power and offers a cost-effective method to analyse material fire performance compared to conventional fire testing [3-7]. Specifically. Large-eddy simulation (LES)-based fire field modelling has become dominant in numerical studies of fire dynamics, with generalised fire codes, such 
as Fire Dynamics Simulator (FDS) [8], FireFOAM [9] and several others [10,11]. Typically, thermogravimetric analysis (TGA) is applied to extract the decomposition kinetics of polymers [12], while the flammability and ignitability of the material can be studied via Cone Calorimetry [3]. Through analysing the thermal degradation at multiple heating conditions (i.e., constant heating rates) $[13,14]$, the resultant pyrolysis rate can be expressed in the form of Arrhenius expression, similar to those applied for gas-phase reactions. For other structural properties, there are Scanning Electron Microscopy and Transmission Electron Microscopy, X-ray Photoelectron Spectroscopy and Small-angle Neutron Scattering [15-17]. There are many successful CFD studies on the fire behaviour of polymer materials. Nguyen et al. [18] investigated the fire resistance of glass fibre reinforced polymer composite via a methodology incorporating experimental (TGA, cone calorimetry and single item burn test) and numerical simulation. The experimental results were used as input parameters and validation to construct the numerical model. The model then provided more detailed insight into the burning process and flame spread behaviour. Dutta et al. [19] conducted a numerical study on natural fibre composites. The pyrolysis kinetics were extracted from TGA experiments and applied in an FDS model of the Cone Calorimeter under horizontal and vertical orientations. More recently, Yuen et al. $[4,20]$ coupled an in-house pyrolysis model with kinetics data extracted via a genetic algorithm to study the thermal decomposition of flame-retardant polyurethane foams. The authors highlighted that a more detailed pyrolysis breakdown of gas products from thermal decomposition could improve the accuracy of smoke and Carbon Monoxide predictions. CFD modelling of polymer pyrolysis is also extensively applied in hybrid rocket engines [21]. Tyurenkova et al. [22-25] conducted a comprehensive series of numerical studies on solid fuel pyrolysis in hybrid rocket engines and investigated the regression behaviour in different flow regimes. It has been found that turbulent transfer coefficients, such as Prandtl number play an essential role to model the gas-solid surface interactions and the regression rate.

Although CFD techniques are widely used to simulate the burning of building materials, there are still many limiting factors from current modelling frameworks. For instance, obtaining material input parameters is one of the major difficulties in conducting fire modelling. It requires quality and reliable data obtained through multiple fire experiments, which are costly and destructive. Furthermore, there are limited techniques to extract the actual chemical composition of emitted volatiles to properly characterise the combustion chemistry in the gas phase and model the solid pyrolysis process [26]. Consequently, single-step gas-phase combustion reactions are often applied instead of detailed chemical kinetics mechanisms [27]. Detailed chemical kinetics would enable a more comprehensive description of gas species and intermediate reactions but are more computationally intensive. As such, molecular dynamics (MD) simulations with a reactive force field (ReaxFF) have significant potential to be applied to gain a more in-depth knowledge of pyrolysis breakdown of material and extract the key input data required for fire modelling.

ReaxFF proposed by van Duin et al. [28] is an empirical bond-order-based reactive forcefield capable of explicitly describing detailed bond breaking, bond formation, and subsequent complex chemical reactions within a molecular system. Owing to the consideration of bond disassociation and bond formation, ReaxFF is a computationally efficient approach to investigate detailed pyrolysis mechanisms of the thermal decomposition process. It can also provide formation pathways of different primary products and extract pyrolysis kinetics in thermal decomposition simulations. Therefore, the adoption of MD simulation would benefit the investigation of polymers' thermal degradation at atomistic levels. For example, Chen et al. [29] characterised the pyrolysis process of three common engineered polymers (high-density polyethylene, poly (methyl methacrylate) and high impact polystyrene) through ReaxFF simulations, obtained detailed pyrolysis kinetics and char formation that was in good agreement with the experimental result. Varri and Paajanen [30] have carried out a ReaxFF based MD simulation to explore the effect of aluminium trihydroxide (ATH) on the thermal decomposition of polyethylene. The simulations replicated the endothermic decomposition of ATH into alumina and water. The simulations also revealed the chemical 
reaction between polyethylene and ATH, such as hydrogen abstraction, water production and enhanced charring. Rahmani et al. [31] examined both non-isothermal and isothermal decomposition of polyethylene oxide using reactive molecular dynamics simulation. The polyethylene oxide was loaded with different concentrations of pristine graphene and graphene oxide nanoplatelets. The result of the MD studies identified improvement in thermal stability by introducing pristine graphene to the polymers. Lan et al. [32] utilised MD simulations to investigate the atomistic behaviours of ammonium polyphosphate filled flame retarded polypropylene composites. The compatibility of flame retardants in the polymer matrix was optimised with different additives, which agrees with experimental data.

All the reviewed works demonstrated MD simulations as a viable tool for investigating the pyrolysis chemistry of polymer systems and highlights the capability to identify the detailed decomposition process from solid to gas phases, which could further act as the precursors of combustible fuel gases in CFD combustion models. Although it is suggested that the turbulent transfer coefficients also plays an essential role, surpassing the molecular transfer coefficients in the numerical investigations [22-25]. MD simulations are able to identify the pyrolysis behaviour and flame retardancy mechanism at the molecular level. This study proposes a multi-scale modelling approach by applying the kinetics parameters and detailed pyrolysis gas volatiles (i.e., parent combustion fuel, key precursor species) extracted from MD to enable detailed chemistry modelling in CFD (see Figure 1). This methodology will deliver a more accurate prediction on polymer degradation, toxicity and smoke emission compared to current assumed CFD models. To investigate the validity of the proposed approach, numerical simulations will be performed on both polyethylene and flame retardant polyethylene. This work is expected to contribute towards future studies investigating the viability of coupling MD with CFD pyrolysis modelling and creating the framework for a fully coupled interactive fire model.

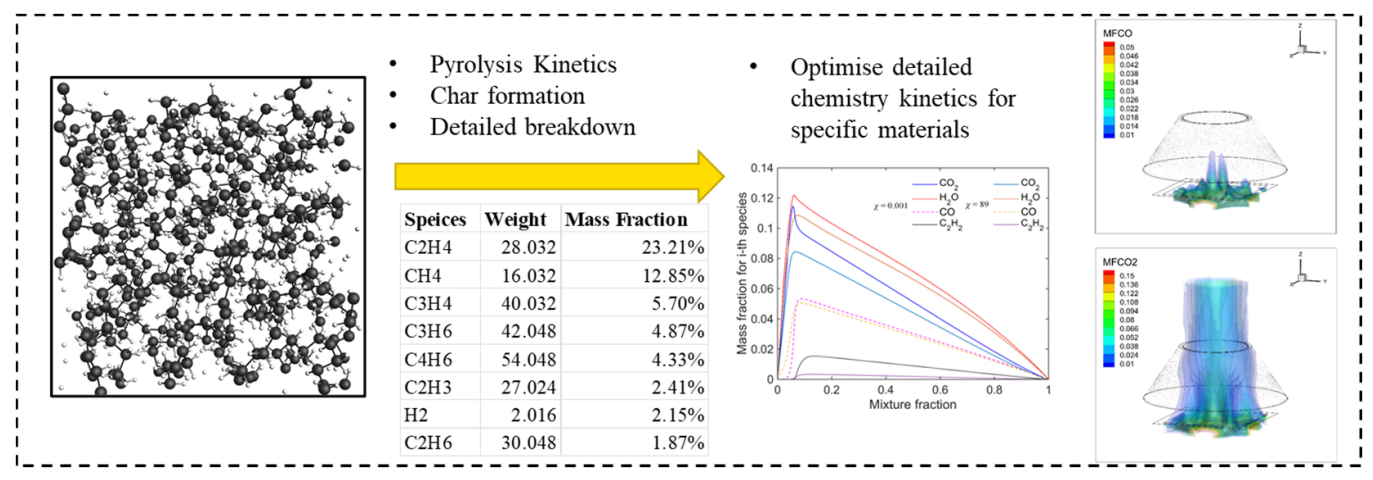

Figure 1. Multi-scale modelling framework incorporating molecular dynamics simulation with computational fluid dynamics.

\section{Results and Discussion}

In order to model the pyrolysis process, the CFD model requires (i) the thermal properties of the material, (ii) the thermal degradation rate and (iii) gas-phase volatile releases involved during the pyrolytic process. Accordingly, instead of extracting these key data from a number of different fire experiments or empirical expressions for the estimation of these quantities, MD (ReaxFF) is employed. Specifically, MD simulations are performed to calculate (i) the thermal conductivity of the polymer system, (ii) the pyrolysis reaction kinetics and (iii) identify the detailed distribution of combustible volatiles of the polymer composites. The data were applied as inputs into a three-dimensional LES fire model comprising of (i) solid pyrolysis, (ii) gas-phase combustion, (iii) radiation heat exchange between fire source, walls, and gaseous products, (iv) soot formation, and (v) sub-grid scale (SGS) turbulence models. Finally, the simulation results are validated against experimental data from cone calorimetry. 


\subsection{Molecular Systems}

Figures 2 and 3 reveal the snapshots of the atomic configurations of pure PE and PE filled with 25 mass percentage (wt\%) ATH during the MD simulations at $3000 \mathrm{~K}$. As can be seen from the snapshots, the detailed disassociation and formation of chemical bonds from the pyrolysis process can be observed at an atomic level over time. In the case of pure PE (Figure 2), the initial status of the simulation begins with the packed amorphous structure in the periodic domain. The bonding force between monomers begins disassociation when sufficient heat energy is applied to the system. Over an instantaneous time (i.e., $10 \mathrm{ps),} \mathrm{it}$ can be observed that the polymer structure initiates the breakdown process, where smaller molecular compounds are formed. With a longer duration of simulation time, there will be a further amount of minor chemical compounds forming. While for the ATH filled PE system (Figure 3), $\mathrm{H}_{2} \mathrm{O}$ molecules are formed owing to the existence of $\mathrm{OH}$ anions from the ATH. Except for the yields of water, it can also be observed that the breakdown of the PE grain is relatively slower than the pure PE system. The results highlight the capabilities of MD to analyse the detailed temporal distribution of the detailed pyrolysis breakdown gas products from thermal decomposition.

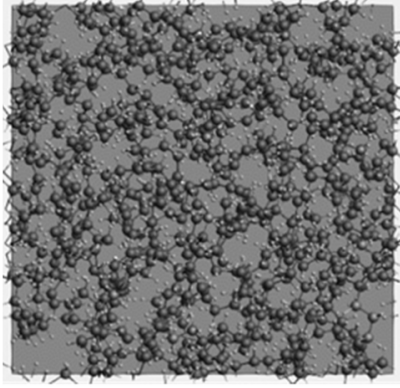

Ops

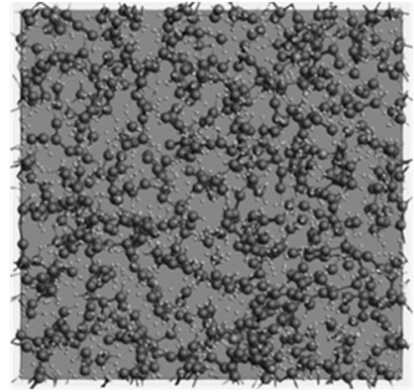

$10 \mathrm{ps}$

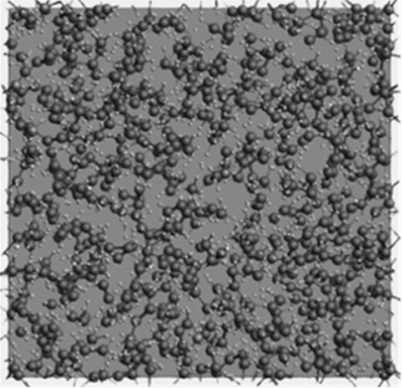

$100 \mathrm{ps}$

Figure 2. Snapshots of the evolving pyrolysis fragments at $3200 \mathrm{~K}$ for the polyethylene (PE) system.

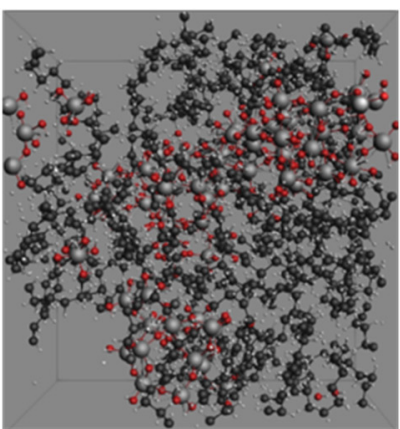

$0 \mathrm{ps}$

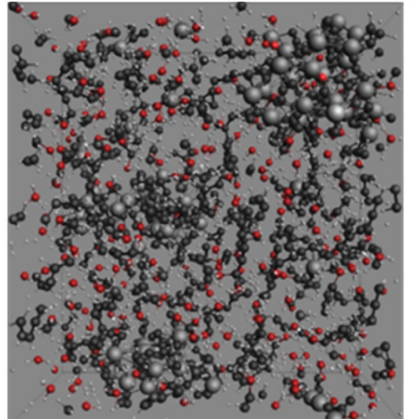

$10 \mathrm{ps}$

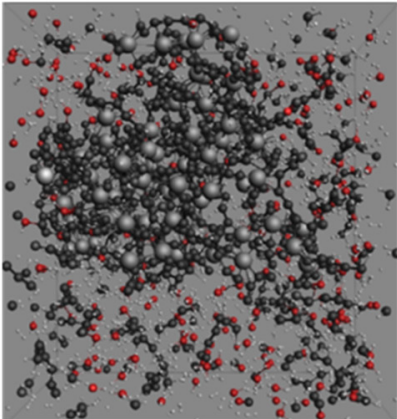

$100 \mathrm{ps}$

Figure 3. Snapshots of the evolving pyrolysis fragments at $3200 \mathrm{~K}$ for the polyethylene with 25 mass percentage aluminium trihydroxide (PE $+25 \mathrm{wt} \% \mathrm{ATH})$ system.

\subsection{Pyrolysis Kinetic Analysis}

In the past few years, there are a few methods that have been investigated to approximate the thermal decomposition of polymers in MD. These include kinetics analysis on (i) the number of monomer molecules [33,34], and (ii) the approximation of mass loss by applying a threshold or cut-off based on carbon (C) number $[35,36]$ or molecular weight [37-39]. This study determined the first-order pyrolysis kinetics by two different analysis approaches. The first approach (MD) analysed the molecular number of the backbone monomer (e.g., ethylene $\left.\left(\mathrm{C}_{2} \mathrm{H}_{4}\right)\right)$ at a temperature ranging from $2800 \mathrm{~K}-3800 \mathrm{~K}$. While in the second approach (MD-CN), the kinetics were estimated by adopting a molecular 
weight cut-off filter at the temperature ranging from $2800 \mathrm{~K}-3800 \mathrm{~K}$. Fletcher et al. suggested that the pyrolysis fragments can be classified as char species/residues $\left(\mathrm{C}_{40+}\right)$, tar species $\left(\mathrm{C}_{5-40}\right)$ and gas species $\left(\mathrm{C}_{0-5}\right)$ based on the containing number of carbon atoms [40]. Figures 4 and 5 demonstrate the time profile of the number of ethylene monomers and weight percentage of $\mathrm{C}_{40+}$ residues in the PE and $\mathrm{PE}+25 \mathrm{wt} \%$ ATH simulations at different temperatures for the first 200 ps.

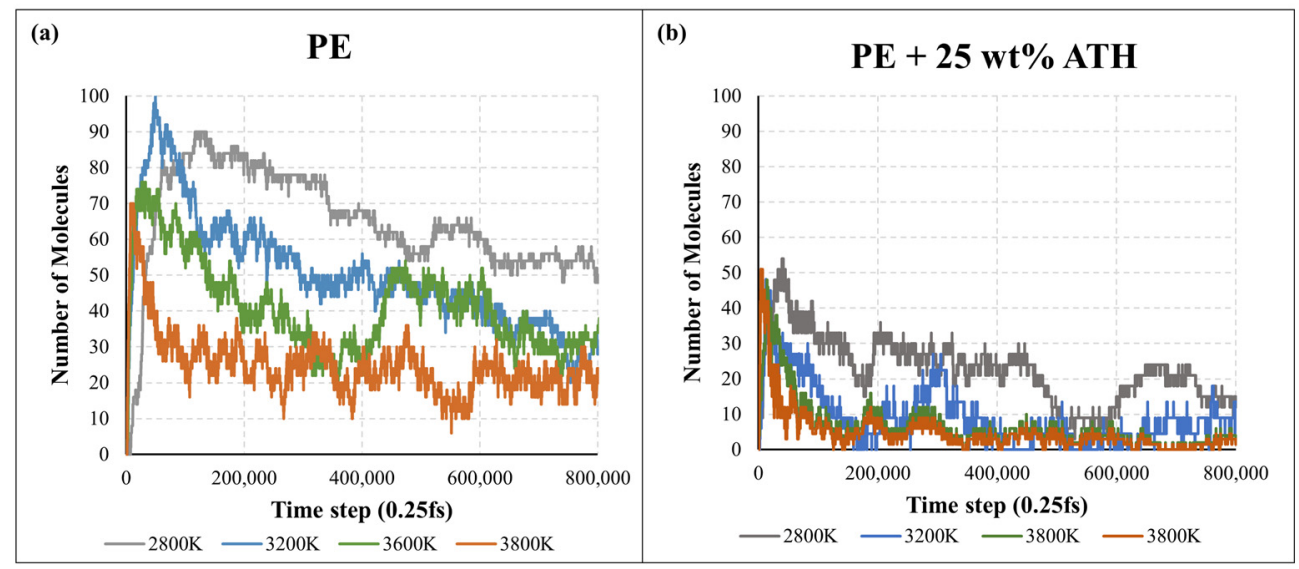

Figure 4. Numbers of $\mathrm{C}_{2} \mathrm{H}_{4}$ molecules for the (a) polyethylene (PE) and (b) polyethylene with $25 \%$ aluminium trihydroxide (PE $+25 \mathrm{wt} \% \mathrm{ATH})$ during the molecular dynamics' simulation.

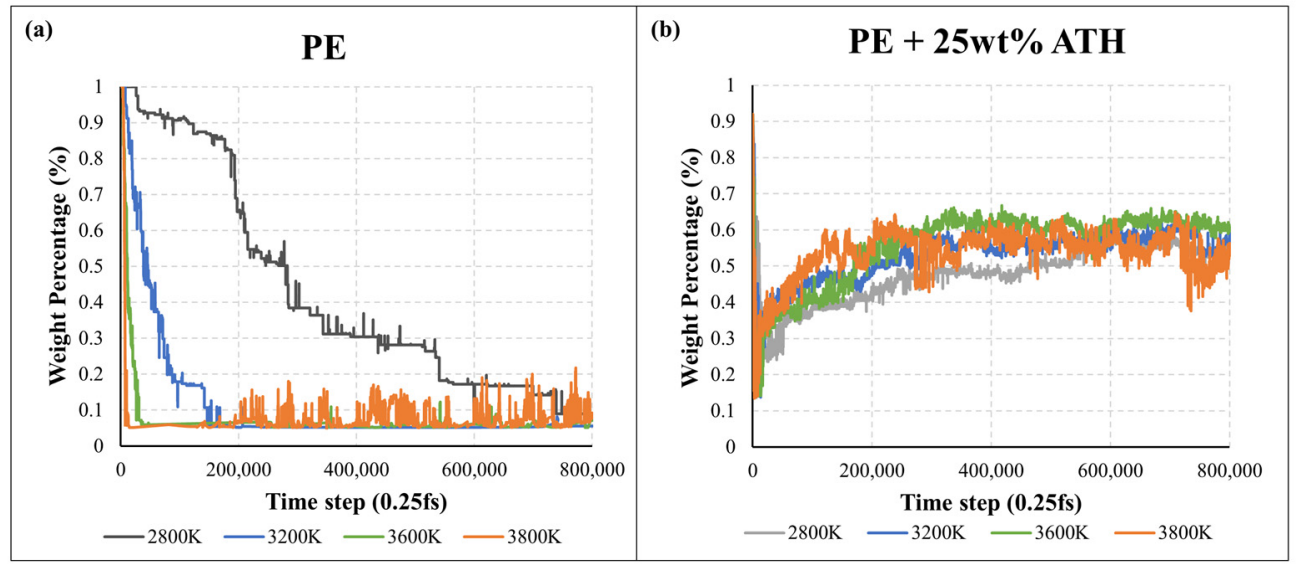

Figure 5. Weight percentage of $\mathrm{C}_{40+}$ for the (a) polyethylene (PE) and (b) polyethylene with $25 \%$ aluminium trihydroxide $(\mathrm{PE}+25 \mathrm{wt} \% \mathrm{ATH})$ during the molecular dynamics simulation.

In Figure 4, a sharp increase in the number of ethylene monomers can be generally observed at the start, indicating the initial breakdown of the polymer into its monomer components. It is followed by a gradual decrease as the monomers break down into subsequent pyrolysis products. It can be clearly seen that the total numbers of ethylene in PE/ATH are less than PE, indicating the polymeric degradation rate of PE/ATH was slower. Figure 5 reveals the weight percentage of $\mathrm{C}_{40+}$ for the PE and PE/ATH during the molecular dynamics simulation. For pure PE (except $2800 \mathrm{~K}$ ), the weight percentage of the pyrolysis fragment was rapidly degraded to $10 \%$ within the first $50 \mathrm{ps}$, indicating the violent decomposition of the polymers without any FR additives. While for PE/ATH (Figure $5 b$ ), the weight percentages of $\mathrm{C}_{40+}$ raised after the initial breakdown of PE during the first 50 ps, indicating the char formation led by the ATH additives. 
As mentioned previously, the pyrolysis kinetics for solid decomposition reaction can be expressed in the form of Arrhenius expression:

$$
r=A \exp \left(\frac{E_{a}}{R T}\right)(Y)^{n}
$$

where $r$ is the reaction rate, $E_{a}$ is the activation energy, $A$ is the pre-exponential, $R$ is the universal gas constant, $T$ is the reaction temperature, $Y$ is the mass fraction of the solid material and $n$ is an exponential factor for the mass fraction. The pyrolysis kinetic parameters $E_{a}$ and $A$ were determined by analysing the correlation between the reaction rate $r_{i}$ and the corresponding pyrolysis temperature $T_{i}$, where $i$ denotes the range of temperature. A linear relationship can be established between $\ln \left(r_{i}\right)$ and $\left(1 / T_{i}\right)$. The theoretical linear relationship between the two terms can be expressed as:

$$
\ln \left(r_{i}\right)=\ln (A)-\frac{E_{a}}{R}\left(\frac{1}{T_{i}}\right)
$$

As illustrated in Figure 6, utilising Equation (2), the pyrolysis kinetic parameters $E_{a}$ and $A$ can be extracted from the slope $\left(-E_{a} / R\right)$ and intercept $(\ln (A))$ of the fitted line. The results are listed in Table 1 . As can be seen, the results derived from MD were aligned with values obtained from TGA and also in the range of the values reported in Sinfronio et al. [41] of 227.33-269.04 for $E_{a}$ and $2.4 \times 10^{13}-1.8 \times 10^{16}$ for $A$. Similarly, these approaches can also be used to extract the reactions for PE/ATH.

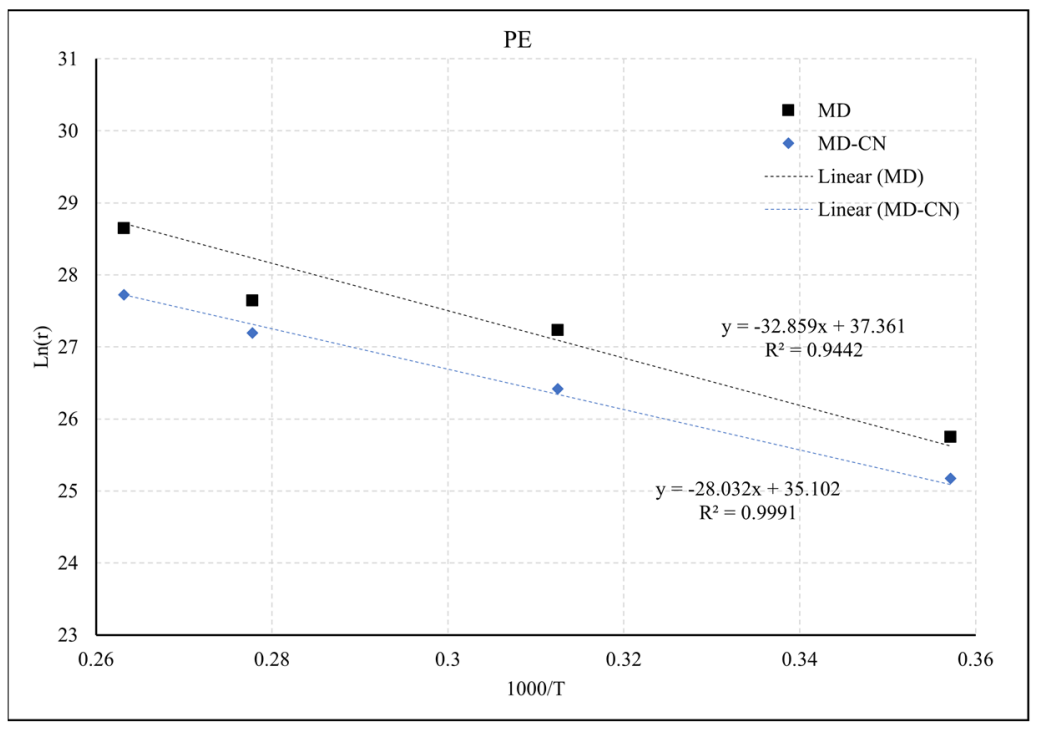

Figure 6. Fitted rate constant versus inverse temperature obtained from the MD simulations based on molecular number of $\mathrm{C}_{2} \mathrm{H}_{4}(\mathrm{MD})$ and cut-off filter by carbon number $\mathrm{C}_{40+}(\mathrm{MD}-\mathrm{CN})$.

Table 1. Pyrolysis kinetic parameters extracted from MD compared with experiments.

\begin{tabular}{cccc}
\hline Polymer Type & & $\boldsymbol{E}_{\boldsymbol{a}} \mathbf{( \mathbf { k J } / \mathbf { m o l } )}$ & $\boldsymbol{A} \mathbf{( \mathbf { 1 } / \mathbf { s } )}$ \\
\hline PE & MD & 273.25 & $1.798 \times 10^{16}$ \\
& MD-CN & 233.06 & $1.76 \times 10^{13}$ \\
& TGA Experiment & 266.74 & $1.52 \times 10^{16}$ \\
PE + ATH & MD & 325.43 & $5.0291 \times 10^{11}$ \\
& MD-CN & 285.41 & $5.03 \times 10^{13}$ \\
\hline
\end{tabular}

For the PE $+25 \%$ ATH case, it can be observed that the breakdown rate of the ethylene of the system was reduced due to the existence of ATH. As illustrated in Figure 7, the formation of $\mathrm{H}_{2} \mathrm{O}$ has significantly occurred in the $\mathrm{PE}+\mathrm{ATH}$ simulations, which further 
consumed hydrogen atoms and reduced the formation of other alkane fuel species (e.g., methane $\mathrm{CH}_{4}$, ethylene $\mathrm{C}_{2} \mathrm{H}_{4}$ and propane $\mathrm{C}_{3} \mathrm{H}_{6}$ ) that requires hydrogen atoms. It can be noticed that the mass fraction of these alkane fuels in PE/ATH is significantly lower than in the pure PE simulations.

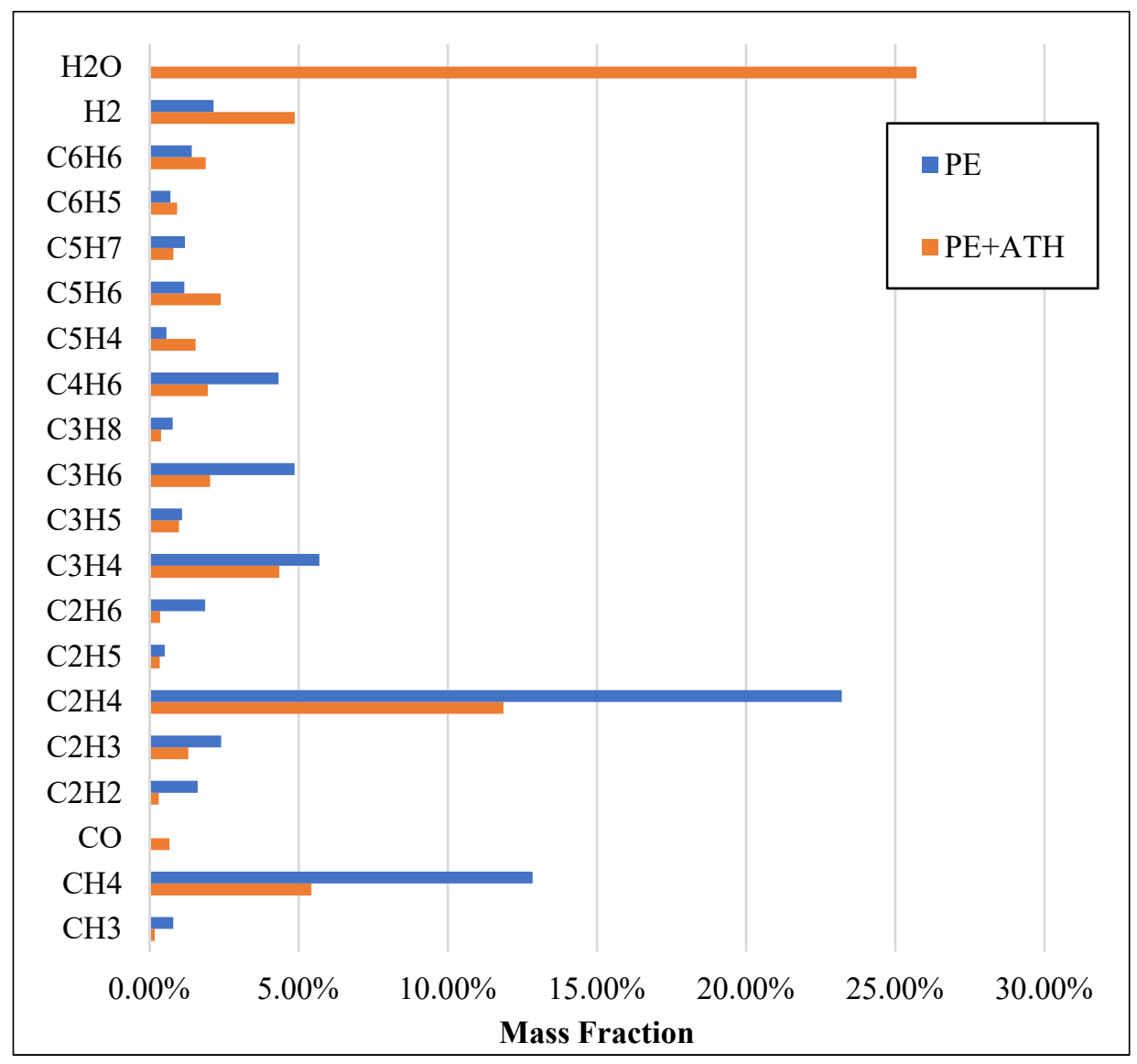

Figure 7. Detailed breakdown of the pyrolysis products for polyethylene (PE) and polyethylene with $25 \%$ aluminium trihydroxide (PE $+\mathrm{ATH})$ arranged by mass fraction.

\subsection{Incorporating MD into Detailed Chemistry Kinetics}

The detailed chemical reaction mechanism GRI-Mech 3.0 [32] and CHEMKIN 19.2 [33] were used to generate the flamelet library for the combustion model. The initial 53 species flamelet library was reduced to 16 species by applying a mixture fraction cut-off to optimise the computational efficiency of the detailed chemistry model. The list of species includes $\mathrm{H}_{2}, \mathrm{H}, \mathrm{O}, \mathrm{O}_{2}, \mathrm{OH}, \mathrm{H}_{2} \mathrm{O}, \mathrm{HO}_{2}, \mathrm{CH}_{3}, \mathrm{CH}_{4}, \mathrm{CH}_{2} \mathrm{O}, \mathrm{CO}, \mathrm{CO}_{2}, \mathrm{C}_{2} \mathrm{H}_{2}, \mathrm{C}_{2} \mathrm{H}_{4}, \mathrm{C}_{2} \mathrm{H}_{6}, \mathrm{C}_{3} \mathrm{H}_{6}, \mathrm{~N}_{2}$. The major selective combustion and toxic species at the maximum and minimum scalar dissipation rates for the three cases are displayed in Figure 8. From the flamelet profiles, it can be observed that the mass fraction of major combustion products, such as $\mathrm{CO}_{2}$ and $\mathrm{H}_{2} \mathrm{O}$ is at a maximum at around the stoichiometric where complete combustion occurs, passing the stoichiometric results in intermediate species, such as $\mathrm{CO}$ and as incomplete combustion occurs.

Figure $8 \mathrm{a}, \mathrm{b}$ shows the flamelet profiles generated using $100 \% \mathrm{C}_{2} \mathrm{H}_{4}$ as the parent fuel and the volatiles gas mixture characterised via MD simulation, respectively. Comparing both profiles, it can be seen that the flamelet profiles from MD simulation resulted in a noticeable decrease in both $\mathrm{CO}$ and $\mathrm{CO}_{2}$ and an increase in $\mathrm{H}_{2} \mathrm{O}$ and $\mathrm{H}_{2}$. More specifically, applying pure $\mathrm{C}_{2} \mathrm{H}_{4}$ as the parent fuel would result in little to no $\mathrm{H}_{2}$ formations, which is unrealistic since it is widely known that significant hydrogen is produced from the polymer pyrolysis process. Subsequently, many fire codes implement a prescribed $\mathrm{H}_{2}$ yield to overcome this issue. Another side point to note is that the scalar dissipation rate close 
to flame extinction is approximately 176 for pure $\mathrm{C}_{2} \mathrm{H}_{4}$ and decreases to approximately 150 when the MD gas mixture was applied. The scalar dissipation represents the level of flame straining/stretching caused by turbulence, leading to the non-uniformity of the mixture fraction from the chemical equilibrium. Focusing on Figure $8 c$, which shows the flamelets profiles for PE/ATH, it can be seen that there is a further decrease in $\mathrm{CO}$ and $\mathrm{CO}_{2}$ formations and is replaced with a significant increase in $\mathrm{H}_{2} \mathrm{O}$ formation. As previously identified from the MD simulation, ATH operates by a dehydration mechanism that releases water vapour $\left(\mathrm{H}_{2} \mathrm{O}\right)$, causing a dilution of combustible gas and oxygen concentration. This dilution effect from ATH is reflected in the combustion flamelet profiles, with reduced combustion resulting in less $\mathrm{CO}$ and $\mathrm{CO}_{2}$ formation.
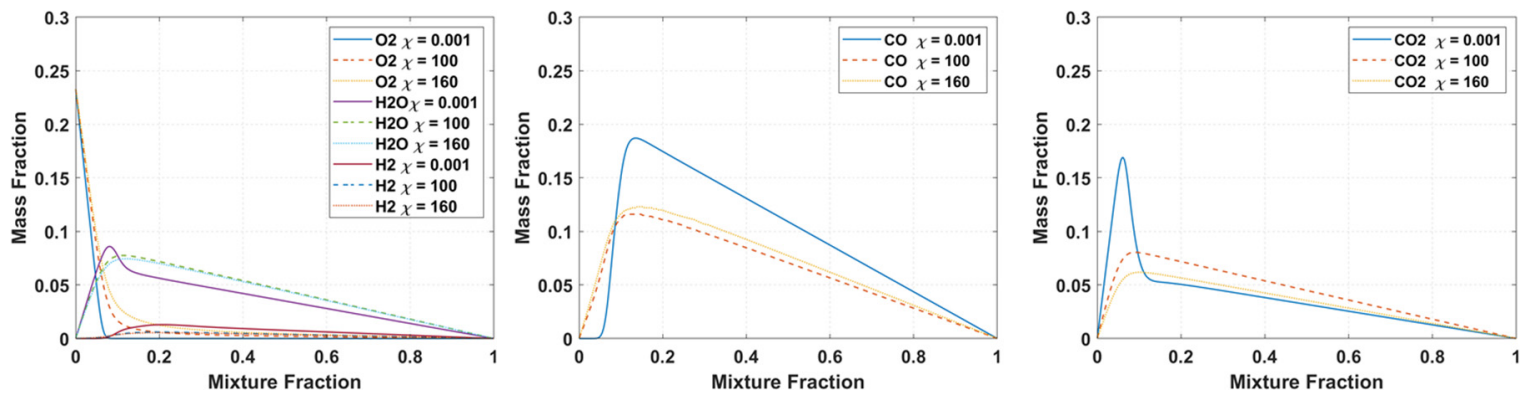

(a) Polyethylene with pure $\mathrm{C}_{2} \mathrm{H}_{4}$ (ethylene) parent fuel
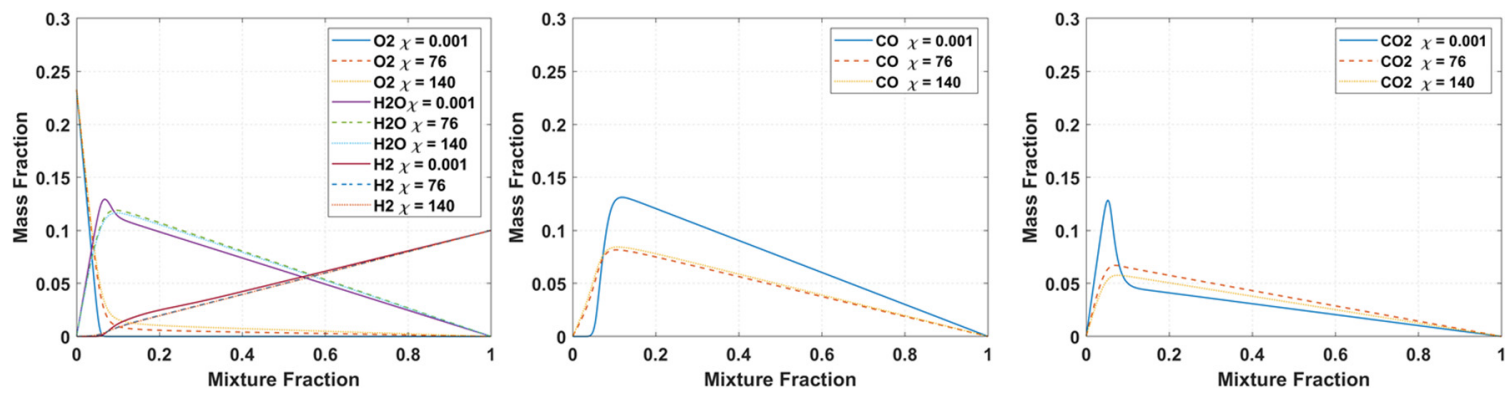

(b) Polyethylene with parent fuel from molecular dynamics (MD) simulation
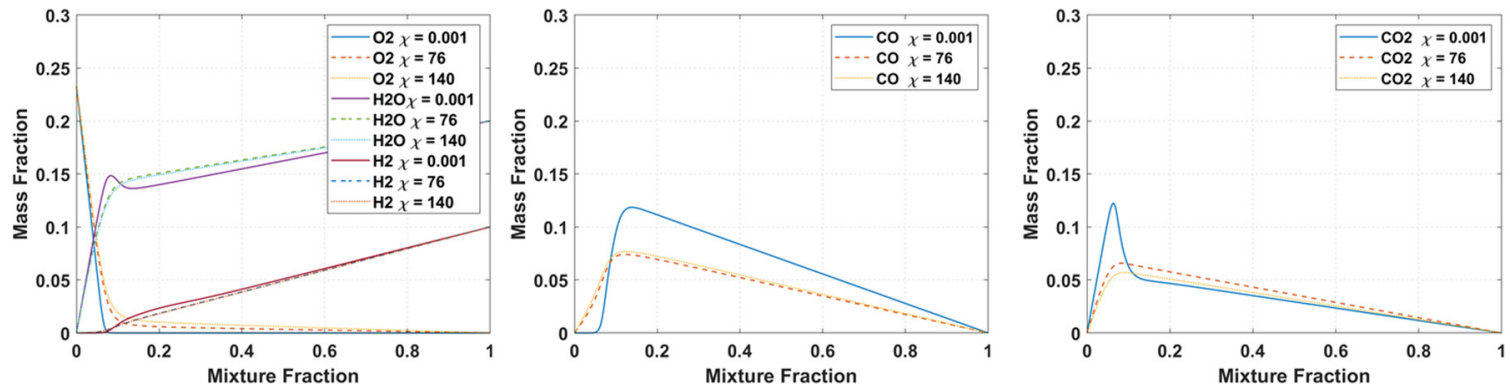

(c) polyethylene with $25 \%$ aluminium trihydroxide $(\mathrm{PE}+25 \mathrm{wt} \% \mathrm{ATH})$

Figure 8. Flamelet profiles for selective major combustion species and carbon monoxide (CO) and carbon dioxide $\left(\mathrm{CO}_{2}\right)$ at different scalar dissipation rates for (a) Polyethylene case with pure $\mathrm{C}_{2} \mathrm{H}_{4}$ (ethylene) parent fuel, (b) Polyethylene case with volatiles gas mixture from molecular dynamics simulation as the parent fuel and (c) polyethylene with $25 \%$ aluminium trihydroxide (PE $+25 \mathrm{wt} \%$ $\mathrm{ATH})$ case with volatiles gas mixture from molecular dynamics simulation as the parent fuel.

\subsection{Cone Calorimeter Simulation}

For validation and verification, numerical simulations have been performed based on the cone calorimeter experiment with computational geometry illustrated in Figure 9. 
The computational domain consists of the cone geometry, and a $60 \mathrm{~mm}$ long cylindrical extended region was applied from the cone outlet with a diameter of $90 \mathrm{~mm}$.

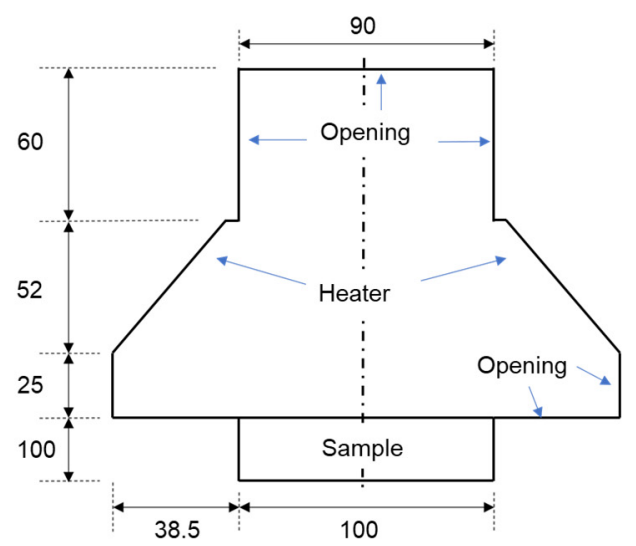

(a)

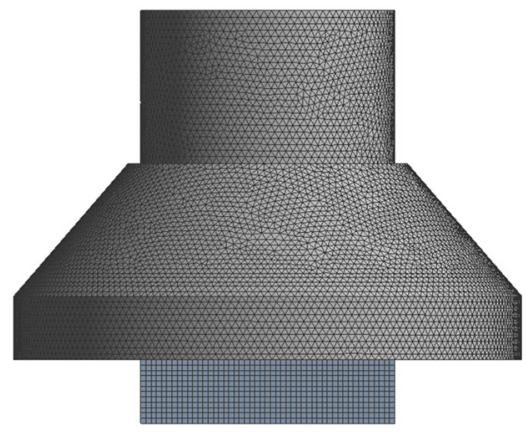

(b)

Figure 9. Diagram of (a) the cone calorimeter geometry with dimensions and (b) the meshed computational domain.

A grid sensitivity analysis was performed on three mesh systems constructed based on the characteristic length analysis [42], detailed in Table 2. The heat release rate profile was used for comparison, as presented in Figure 10. The heat release rate for the first 50 $\mathrm{s}$ was used to analyse mesh convergence to reduce the computational time required for the test. The results show that the ignition time changed significantly from approximately $5.50 \mathrm{~s}$ for the coarse mesh to $2.37 \mathrm{~s}$ for the medium mesh (56.9\% difference). Comparing the medium to fine mesh, the ignition time further converged from $2.37 \mathrm{~s}$ to $2.12 \mathrm{~s}$ with a difference of $6.3 \%$. Furthermore, it can be observed that the mesh refinement resulted in a decrease in the overall heat release rate and converged to match more closely with the experimental data. Considering the convergence results, the $1.5 \mathrm{~mm}$ uniform mesh was adopted in this numerical simulation.

Table 2. Details of the mesh systems used in the mesh sensitivity analysis.

\begin{tabular}{ccc}
\hline Mesh & Mesh Size (mm) & Total Number of Cells \\
\hline Mesh 1 (coarse) & 5 & 676,875 \\
Mesh 2 (medium) & 2 & $1,353,750$ \\
Mesh 3 (fine) & 1.5 & $3,210,000$ \\
\hline
\end{tabular}

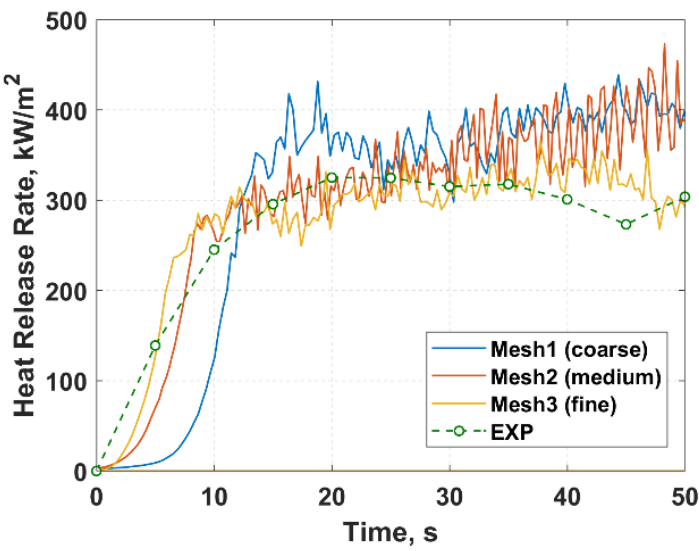

Figure 10. Mesh sensitivity comparison of the heat release rate profile for the three mesh systems. 
Figure 11a presents the numerically predicted heat release rate (HRR) profiles of the polyethylene cone simulations incorporating pure $\mathrm{C}_{2} \mathrm{H}_{4}$ (ethylene) and volatiles gas mixture from molecular dynamics simulation as the combustion chemical kinetics fuel precursors. The overall experimental trend of the heat release rate profiles was successfully captured in the numerical simulations. The single heat release rate peak predicted by the numerical model was in agreement with experimental data. Furthermore, considering the evaluated fuel gas volatile composition resulting from the MD pyrolysis breakdown delivers a more realistic HRR profile that closely matches the cone calorimeter experiment. In contrast, the assumption that pure $\mathrm{C}_{2} \mathrm{H}_{4}$ as the parent fuel yielded an overestimation of the HRR profile since the purity of the combustible volatile by right should not be $100 \%$ after the pyrolytic reactions, which this behaviour can be reflected in the MD model.

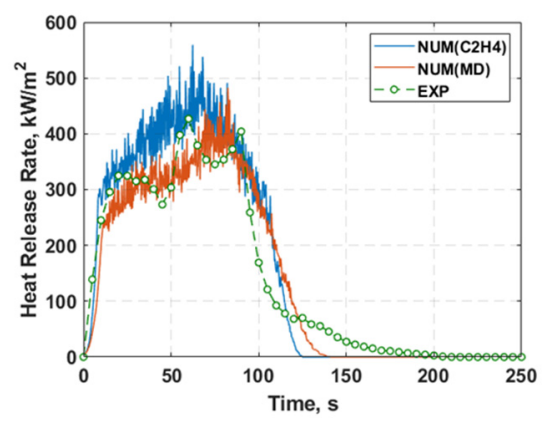

(a)

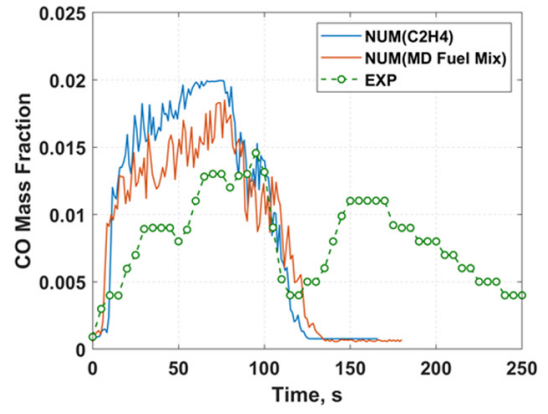

(b)

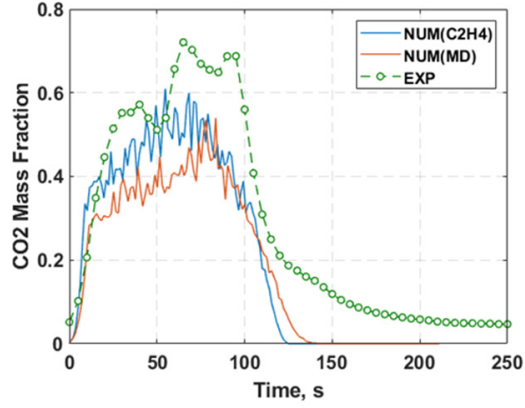

(c)

Figure 11. Comparison of numerical results against experimental (a) heat release rate (HRR), (b) carbon monoxide $(\mathrm{CO})$ and $(\mathrm{c})$ carbon dioxide $\left(\mathrm{CO}_{2}\right)$ profile from cone calorimetry under a heat flux of $35 \mathrm{~kW} / \mathrm{m}^{2}$ for (i) Polyethylene case with pure ethylene $\left(\mathrm{C}_{2} \mathrm{H}_{4}\right)$ parent fuel, and (ii) Polyethylene case with volatiles gas mixture from molecular dynamics (MD) simulation as the parent fuel.

Figure $11 \mathrm{~b}, \mathrm{c}$ show the concentrations of the carbon monoxide (CO) and carbon dioxide $\left(\mathrm{CO}_{2}\right)$ contents at the top cone outlet of the computational domain compared to experimental measurements. The results present the effects of changing the parent fuel based on molecular dynamics simulation on the formation of toxic by-products. It can be observed that by assuming the combustion fuel precursor to be purely $\mathrm{C}_{2} \mathrm{H}_{4}$, the amount of $\mathrm{CO} / \mathrm{CO}_{2}$ concentrations generated is greater than that compared to the cases with the MD inputs.

Figure 12 illustrates the numerically predicted heat release rate profiles of the simulations between PE and PE/ATH based on MD input. As shown in Figure 12a, the peak heat release rate was reduced by $34.2 \%$ compared to pure PE. It can be observed that the reduction in heat release rate led by the addition of ATH flame retardant is replicated in the cone simulations.

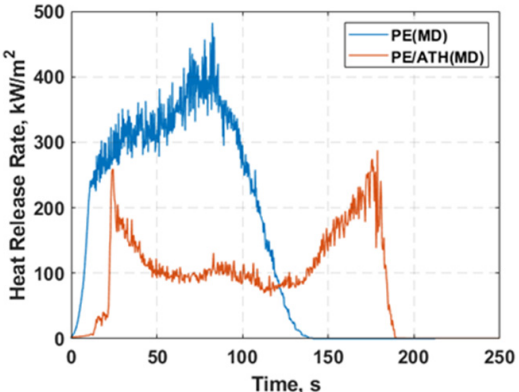

(a)

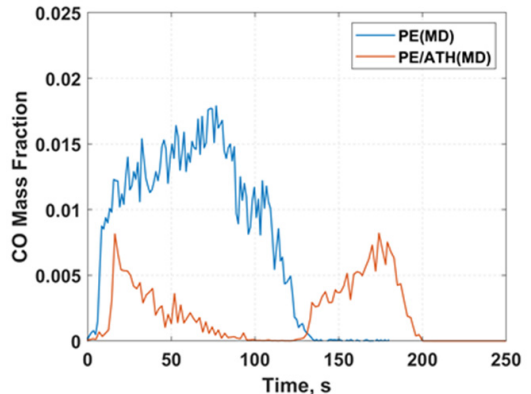

(b)

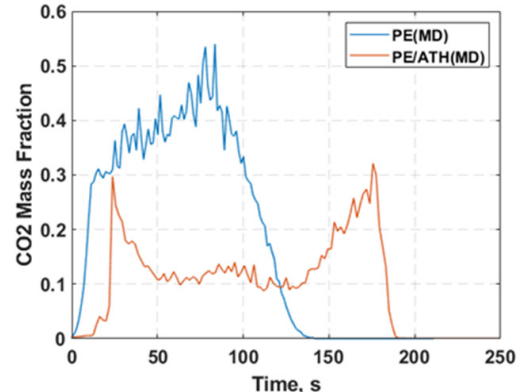

(c)

Figure 12. Comparison of numerical results against experimental (a) heat release rate (HRR), (b) Carbon Monoxide (CO) and (c) Carbon Monoxide $\left(\mathrm{CO}_{2}\right)$ profile from cone calorimetry under a heat flux of 35 $\mathrm{kW} / \mathrm{m}^{2}$ for (i) Polyethylene (PE) and (ii) polyethylene with aluminium trihydroxide (PE/ATH) case with volatiles gas mixture from molecular dynamics (MD) simulation as the parent fuel. 
The concentration of $\mathrm{H}_{2} \mathrm{O}$ species for the PE/ATH simulation applying $\mathrm{C}_{2} \mathrm{H}_{4}$ and $\mathrm{MD}$ inputs as the parent fuel is depicted in Figure 13. The generation of $\mathrm{H}_{2} \mathrm{O}$ species translates to water vapour formation, which is generally recognised as one of the major fire suppression mechanisms. As can be seen from the figure, the amount of $\mathrm{H}_{2} \mathrm{O}$ content significantly increases from PE/ATH when the MD inputs were applied compared to a pure reaction fuel. As mentioned previously, the intrinsic vaporisation properties of ATH when incorporated into PE promote a supplementary chemical pathway for rapid vaporisation, leading to increased moisture level after the pyrolytic process. Therefore, before exhibiting the combustion process, there was a considerable $\mathrm{H}_{2} \mathrm{O}$ content. In addition, the increased formation of $\mathrm{H}_{2} \mathrm{O}$ will also result in a reduction in combustible fuel gas volatile, thus further lowering the heat release rate during the burning process. The result demonstrates the application of the proposed MD framework to extract the flame retardant mechanisms to the CFD combustion model and provide a better representation of the gas decomposition process. It allows the CFD model to simulate the underlying flame retardant mechanism offered by ATH that suppresses the peak heat release rate.

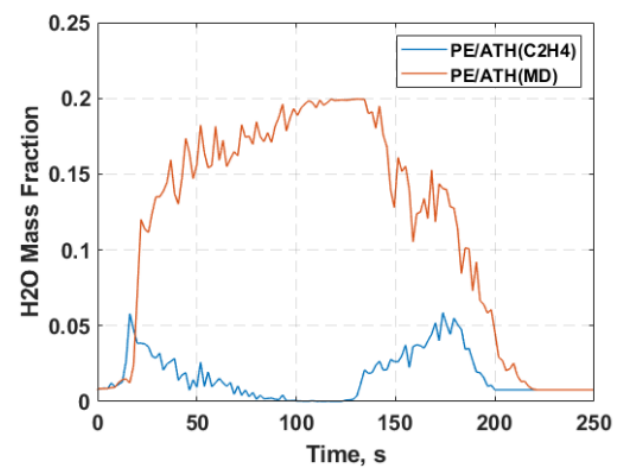

Figure 13. Numerical results for $\mathrm{H}_{2} \mathrm{O}$ mass fraction profile from cone calorimetry under a heat flux of $35 \mathrm{~kW} / \mathrm{m}^{2}$ for polyethylene with aluminium trihydroxide (PE/ATH) case with (i) pure $\mathrm{C}_{2} \mathrm{H}_{4}$ (ethylene) and (ii) volatiles gas mixture from molecular dynamics (MD) simulation as the parent fuel.

\section{Materials and Methods}

The mathematical models and characterisation methods are presented in the following sections.

\subsection{Molecular Dynamics}

ReaxFF is an empirical bond-order-based reactive forcefield and can explicitly describe chemical reactions within complex systems. It is commonly applied to describe the general relationship between bond distance and bond order and between bond order and bond energy. This complex interaction leads to the proper dissociation of bonds to separated atoms. The molecular movement and inter-atomic interactions are governed by Newton's second law:

$$
\begin{aligned}
\sum F=m a & =m \frac{d v}{d t}=m \frac{d^{2} x}{d t^{2}} \\
F & =-\nabla E
\end{aligned}
$$

where $F$ is the instantaneous force acting on a particle with mass $m$, acceleration $a, v$ and $x$ are the instantaneous particle velocity and position respectively, and $t$ is the time. $E$ the potential energy function and $\nabla$ is the differential operator. MD is based on the general relationship between bond distance and bond order and the bond energy that leads to the dissociation of bonds to separate atoms. The energy function can be determined by:

$$
E_{\text {system }}=E_{\text {bond }}+E_{\text {over }}+E_{\text {under }}+E_{\text {val }}+E_{\text {pen }}+E_{\text {tors }}+E_{\text {conj }}+E_{\text {vdWaals }}+E_{\text {Coulomb }}
$$


where all the $E$ terms present the energy associated with the bond, over-and undercoordinated atom, valence angle term, penalty energy, torsion energy, conjugation effects to molecular energy, nonbonded van der Waals interaction and Coulomb interaction, respectively. The LAMMPS Molecular Dynamics Simulator [43] was applied to perform the numerical simulations. The reac/c package [44] was used to compute the ReaxFF potentials.

\section{Molecular System Configuration and Simulation Details}

In the current study, two materials were considered in the ReaxFF simulations, namely $\mathrm{PE}$ and aluminium trihydroxide (ATH). Owing to the existence of aluminium atoms, the reactive forcefield "AlCHO" proposed by Hong et al. was adopted [45]. Firstly, the molecular structure of PE was constructed by the compression of linear polymer chains, followed by an annealing process to form an amorphous structure, where the initial structures were slowly heated from $300 \mathrm{~K}$ to $600 \mathrm{~K}$ and rapidly quenched to $300 \mathrm{~K}$. The subsequently annealed geometries were then relaxed using a conjugate gradient minimisation scheme. The initial model structure was created by PACKMOL [46] comprising of 4 linear PE chains $(\mathrm{n}=50)$ in a $20 \mathrm{~nm} \times 20 \mathrm{~nm} \times 4 \mathrm{~nm}$ simulation box (200 carbon atoms in total), with a density of $0.93 \mathrm{~g} / \mathrm{cm}^{3}$. Similar to the approach adopted by Varri and Paajanen [30], Gibbsite was introduced to represent the crystal structure of ATH, where two dioctahedral layers are related horizontally. The monoclinic unit cell comprised of two planes has $16 \mathrm{Al}(\mathrm{OH})_{3}$ units. Five unit cells $\left(80 \mathrm{Al}(\mathrm{OH})_{3}\right.$ units, 560 atoms) were then implemented through PACKMOL to achieve the proposed weight percentage in the current study $(25 \mathrm{wt} \%)$. The final structures of the PE and PE/ATH are shown in Figure 14. For the thermal decomposition simulations involving pure PE and PE/ATH composites, the temperature and pressure of the system were regulated using the Nose-Hoover thermostat and barostat with a damping coefficient of $100 \mathrm{fs}$ [47]. Various MD-ReaxFF studies on polymer degradation have suggested high artificial temperatures to promote sufficient atomic motion and molecular collision, with reasonable computational cost $[29,36,48-51]$. Hence, the simulations were carried out for $200 \mathrm{ps}$ in a range of artificial temperature from $2800 \mathrm{~K}$ to $3800 \mathrm{~K}$ for PE and PE/ATH composites pyrolysis analysis.

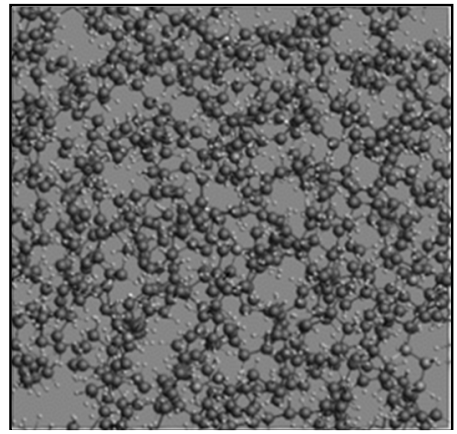

(a)

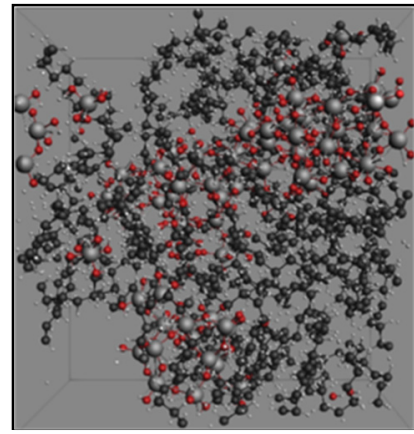

(b)

Figure 14. Amorphous structure of the (a) PE and (b) PE + ATH system.

\subsection{Computational Fluid Dynamics}

The fire model was developed using ANSYS Fluent version 19.2, extending a threedimensional porous media pyrolysis model from previous work [4]. The solid pyrolysis model was developed with user-defined functions (UDF) which describe the solid thermal degradation process and porous properties of the sample. UDF allows customization for boundary conditions [52], material properties [53,54], source terms [4] and model parameters $[55,56]$. The Wall-Adapting Local Eddy-viscosity was employed to resolve the subgrid-scale eddies, and the Moss-Brookes semi-empirical soot model was implemented to handle the soot concentration within the cone computational domain [57]. The complex fluid motion and heat transfer of a turbulent reacting non-premixed diffusion flame 
is governed by the equations of mass, momentum and energy. Conservation of scalar properties, such as gas chemical species is governed by a transport equation. For practical simulation of a weak buoyancy-driven flame, several assumptions are made including (i) the low Mach number flow equations are considered, (ii) the thermophysical properties are constant and (iii) the ratio between mass and thermal diffusivity (Lewis number) is unity $[58,59]$. Accordingly, the following form of the governing equations are utilised in this simulation study:

Mass conservation equation:

$$
\frac{\partial \rho}{\partial t}+\nabla \cdot(\rho u)=S_{m}
$$

Momentum conservation equation:

$$
\frac{\partial \bar{\rho} \widetilde{u_{i}}}{\partial t}+\frac{\partial}{\partial x_{i}}\left(\bar{\rho} \widetilde{u}_{i} \widetilde{u}_{j}\right)=-\frac{\partial \bar{p}}{\partial x_{i}}-\frac{\partial \bar{\tau}_{i j}}{\partial x_{j}}-\frac{\partial \tau_{i j}^{s g s}}{\partial x_{j}}+\bar{\rho} g+\overline{\dot{m}_{b}^{\prime \prime \prime} \widetilde{u_{b}, i}}
$$

The term $\dot{m}_{b}^{\prime \prime \prime} u_{b, i}$ represents the bulk source term and $\tau_{i j}^{s g s}$ are the subgrid-scale stresses. Energy conservation equation:

$$
\frac{\partial}{\partial t}\left(\rho h_{s}\right)+\nabla \cdot\left(\rho h_{s} u\right)=\frac{D \bar{p}}{D t}+\dot{Q}_{c}^{\prime \prime}-\dot{Q}^{\prime}
$$

where $\dot{Q}_{c}^{\prime \prime}$ represents the heat release rate per unit volume from a combustion reaction and $\dot{Q}^{\prime \prime}$ denotes the conductive, diffusive, and radiative heat fluxes:

$$
\dot{Q}^{\prime \prime}=-k \nabla T-\sum_{\alpha} h_{s, \alpha} \rho D_{\alpha} \nabla Z_{\alpha}+\dot{Q}_{r}^{\prime \prime}
$$

where $k$ is the thermal conductivity and $D_{\alpha}$ is the diffusivity of species $\alpha$.

\subsubsection{Pyrolysis Model}

For the pyrolysis model, it is assumed that: (i) the release of fuel is instantaneous, (ii) there are no porosity and moisture effects, and (iii) the fuel is injected at the surface of the pyrolysing solid. The pyrolysis process is driven by the solid fuel temperature $T_{s}$.computed by the one-dimensional heat conduction equation at the direction to the depth of the solid fuel:

$$
\rho_{s} \mathcal{C}_{s} \frac{\partial T_{s}}{\partial t}=\frac{\partial}{\partial x}\left[k_{s} \frac{\partial T_{s}}{\partial x}\right]+\dot{Q}_{p}^{\prime \prime}+\dot{Q}_{r}^{\prime \prime}
$$

The source terms $\dot{Q}_{p}^{\prime \prime}$ and $\dot{Q}_{r}^{\prime \prime}$ refers to the net heat gain due to chemical reactions during pyrolysis and radiation absorption, respectively. The pyrolysis source term can be determined by the equation:

$$
\dot{Q}_{p}^{\prime \prime}=-\rho_{s} \sum_{i=1}^{N_{R}} r_{i} \Delta H_{r, i}
$$

where $H_{r, i}$ is the heat of reaction and $r_{i}$ is the thermal degradation rate computed in the form of the Arrhenius expression:

$$
r_{i}=c_{i}\left(\frac{\rho_{s}}{\rho_{s 0}}\right)^{n_{i}} A_{i} \exp \left(\frac{-E_{a, i}}{R T_{S}}\right)
$$

As thermal degradation can consist of multiple parallel reaction mechanisms, the $i$ subscript denotes the individual reaction components with the corresponding mass fraction $c_{i}$ and pyrolysis kinetic parameters $E_{a, i}$ and $A_{i}$. The total thermal degradation rate is determined 
by the sum of all reaction components and the amount of fuel releases $\dot{m}_{f u e l}$ released at the material surface is provided as:

$$
\dot{m}_{f u e l}=\rho_{s} V \sum_{i=1}^{N_{R}} r_{i}
$$

where $V$ is the unit cell volume. It is assumed that the mass loss is fully converted into the parent fuel of the combustion model.

\subsubsection{Turbulence}

The Wall-Adapting Local Eddy-viscosity (WALE) model developed Nicoud and Ducros [60], is based on the Smagorinsky [61] LES framework but is more effective at near-wall conditions and wall-bounded flows. The turbulent viscosity $\mu_{T}$ is given by:

$$
\mu_{T}=\rho L_{s}^{2} \frac{\left(S_{i j}^{d} S_{i j}^{d}\right)^{\frac{3}{2}}}{\left(\overline{S_{i j} S_{i j}}\right)^{\frac{5}{2}}+\left(S_{i j}^{d} S_{i j}^{d}\right)^{\frac{5}{4}}}
$$

The mixing length for sub-grid scales $L_{s}$ and rate-of-strain tensor $S_{i j}^{d}$ are determined in the following equations:

$$
\begin{gathered}
L_{s}=\min \left(\kappa d, C_{w} \Delta\right) \\
S_{i j}^{d}=\frac{1}{2}\left(\widetilde{g}_{i j}^{2}+\widetilde{g}_{j i}^{2}\right)-\frac{1}{3} \delta_{i j}, \widetilde{g}_{i j}^{2}=\frac{\partial \widetilde{u}_{i}}{\partial x_{j}}
\end{gathered}
$$

$C_{w}$ is the WALE model constant, prescribed as 0.5 validated previously for various fire simulation studies $[62,63]$. WALE detects the turbulent structure by the combination of strain and rotations rate so that the turbulent viscosity term will be null naturally at the wall boundary without the inclusion of a damping function.

\subsubsection{Detailed Chemistry Combustion}

The strained laminar flamelet model for non-premixed combustion has been adopted. It assumes the fuel burns instantly when mixed with the oxidiser. The combustion chemical source term which appears in the energy equation is calculated based on a fast-chemistry mixture fraction model. In this model, the detailed chemical kinetics of the oxidation process of the parent fuel was considered using the strained laminar flamelet approach. The temperature and chemical species generation (denoted by $m$ ) is determined by the multiple flamelets $(M)$ as a function of mixture fraction $f$, fluctuation of mixture fraction $f^{\prime}$, and scalar dissipation term $\chi$ :

$$
m=\iint M(f, \chi) P\left(f, \chi, f^{\prime}\right) d f d \chi
$$

where $P$ is the corresponding beta probability density function (PDF). The scalar dissipation $\chi$ is introduced to depict the level of flame straining/stretching leading to the non-uniformity of mixture fraction from the chemical equilibrium. The scalar dissipation is given by:

$$
\chi=C_{x} \frac{\left(\mu+\mu_{T}\right)}{\rho \sigma_{T}}|\nabla f|^{2}
$$

The amount of heat generation via combustion is thus determined by the summation of species mass fraction multiplying its heat of formation.

$$
\dot{Q}_{c}^{\prime \prime}=\frac{1}{2} \rho \chi \sum_{i=1}^{N}\left[\int_{0}^{1}\left(h_{s_{i}} \frac{\partial^{2} M_{i}}{\partial \zeta^{2}} P\left(\zeta, \zeta^{\prime}, \chi\right)\right) d \zeta\right]
$$


where $h_{s_{i}}$ depicts the heat of formation of the corresponding $i$-th species. The detailed chemical reaction mechanism GRI-Mech 3.0 [64] and CHEMKIN 19.2 [65] was used to generate the flamelet library for the combustion model. GRI-Mech 3.0 is very well-validated and shown to produce accurate and reliable results for alkane fuels $[11,55,58]$.

\subsubsection{Soot Formation}

The Moss-Brookes semi-empirical soot model [57] was implemented where acetylene is considered as the soot precursor. Numerical studies have shown that the Moss-Brookes soot model combined with detailed kinetics results in significant improvements in the prediction of soot volume fraction [66,67]. This model is a two-equation semi-empirical soot model where acetylene is considered as the soot precursor and solves transport equations for normalised radical nuclei concentration $b_{n u c}^{*}$ and soot mass fraction $Y_{\text {soot }}$ :

$$
\begin{gathered}
\frac{\partial}{\partial t}\left(\rho Y_{\text {soot }}\right)+\nabla \cdot\left(\rho Y_{\text {soot }} \widetilde{u}\right)=\nabla \cdot\left(\frac{\mu_{t}}{\sigma_{\text {soot }}} Y_{\text {soot }}\right)+\frac{d M_{\text {soot }}}{d t} \\
\frac{\partial}{\partial t}\left(\rho b_{n u c}^{*}\right)+\nabla \cdot\left(\rho b_{n u c}^{*} \widetilde{u}\right)=\nabla \cdot\left(\frac{\mu_{t}}{b_{n u c}^{*}} b_{n u c}^{*}\right)+\frac{1}{10^{15}} \frac{d N_{\text {soot }}}{d t}
\end{gathered}
$$

where $M_{\text {soot }}$ is the soot mass concentration, $N_{s}$ denotes soot particle number density.

\subsubsection{Radiation}

The radiative heat transfer was modelled using the filtered radiative transfer equations (FRTE) for non-scattering gray gas solved by the discrete ordinates method (DOM) with the S4 quadrature scheme [68]. The discrete radiation source term $\dot{Q}_{r}^{\prime \prime}$ that appears in the energy equation is determined as:

$$
\dot{Q}_{r}^{\prime \prime}=-4 \bar{k}_{a} E_{b}+\sum_{j=1}^{24} w_{j} \bar{k}_{a} \bar{I}_{j}
$$

where the blackbody radiation is represented by $E_{b}=\sigma T^{4}, \sigma$ is the Stefan-Boltzmann constant and $\bar{I}_{j}$ is the radiation intensities that span over the solid angles range of $4 \pi$ around a point in space. The filtered gas absorption coefficient $\bar{k}_{a}$ was determined as a summation of the gas absorption coefficient approximated using the Weighted Sum of Gray Gases Model [69] and soot [70].

\subsection{Experiment}

\subsubsection{Thermogravimetry}

Thermogravimetry is a proven method to study the thermal decomposition of a material. The thermal gravimetric (TGA) analysis was carried out on a Netzsch TG 209 F3 Tarsus thermoanalyser instrument (Netzsch, Selb, Germany) from room temperature $\left(21^{\circ} \mathrm{C}\right)$ to $1000{ }^{\circ} \mathrm{C}$ in a nitrogen atmosphere under three different heating rates, namely 5 , 10 and $20 \mathrm{~K} / \mathrm{min}$. The specimens were approximately $10 \mathrm{mg}$ in mass, and each test was performed twice to ensure consistency of the data.

\subsubsection{Cone Calorimetry}

The flammability (i.e., heat release) of the material samples was examined via Cone Calorimetry according to ISO 5660 standards to study the flaming behaviour (i.e., ignition time, heat release rate and burn duration) and their corresponding smoke, $\mathrm{CO}_{2}$ and $\mathrm{CO}$ production. The tests were performed on an iCone Classic Calorimeter (Fire Testing Technology, East Grinstead, UK). All samples were cut to $100 \mathrm{~mm} \times 100 \mathrm{~mm}$, then wrapped in aluminium foil with the upper surface exposed. The distance between the cone heater and test surface was set as $25 \mathrm{~cm}$. The measurements were carried out by mounting the sample holder in the horizontal position under atmospheric conditions with a nominal 
exhaust fan airflow rate of $0.0026 \mathrm{~m}^{3} / \mathrm{s}$ for all experiments. Three samples of each material were examined under $35 \mathrm{~kW} / \mathrm{m}^{2}$ incident heat flux.

\section{Conclusions}

The fundamental thermal degradation process from solid fuel to gas volatiles is still one of the major challenges in the field of pyrolysis modelling. A multi-scale modelling approach was proposed to address this significant knowledge gap by applying the kinetics parameters and detailed pyrolysis gas volatiles (i.e., parent combustion fuel, key precursor species) extracted from Molecular Dynamics (MD) to enable a more realistic detailed chemistry combustion in Computational Fluid Dynamics (CFD) fire model. This multiscale modelling is a potential technique for the simulation of combustible polymer materials, as it allows to describe them without the need of performing costly experiments. In this study, the key properties associated with the burning behaviour of pure polyethylene (PE) and polyethylene with aluminium trihydroxide (PE/ ATH) were analysed by molecular dynamics simulations. The microscopic pyrolysis behaviours of the polymers investigated by molecular dynamics were in agreement with the TGA data. The pyrolysis reaction kinetics were successfully calculated by analysing the breakdown rate of the underlying monomer structures at different temperatures. Focusing on the PE with ATH, the MD simulations were able to show the pyrolysis process as the ATH component leads to the increased formation of $\mathrm{H}_{2} \mathrm{O}$ molecules. Subsequently, it leads to a reduced amount of combustible fuel gas volatile, thus reducing the combustion by-products and heat release rate.

From the MD simulations, the material kinetics parameters were directly applied as inputs into a CFD pyrolysis model to simulate cone calorimeter experiments. The model incorporates strained laminar combustion modelling with detailed chemical kinetics, soot formation, subgrid scale turbulence, and radiation models. Furthermore, the detailed pyrolysis gas volatiles from MD was applied to generate the flamelet library for the combustion model. The overall trend of the heat release rate profiles was successfully captured in the numerical simulation. The carbon dioxide and carbon monoxide comparisons were also aligned with experimental results. Furthermore, considering the evaluated fuel gas volatile composition resulting from the molecular dynamics pyrolysis breakdown delivers a more realistic heat release rate profile that closely matches the cone calorimeter experiment than using a single parent fuel.

To summarise, the utilisation of the MD model delivers an in-depth understanding of the pyrolysis and chemical decomposition of molecules of the polymer composites. This allows us to realise the composition of fuel gas volatiles and incorporate them into CFD simulations models with a detailed chemistry combustion sub-module to interpret the data. The underlying flame retardant mechanisms can be described from a fundamental chemistry standpoint through this proposed framework. For instance, the rapid vaporisation effect offered by ATH was studied and its influence on the heat release rate reductions and chemical by-products formations were identified.

Author Contributions: Conceptualization, T.B.Y.C. and A.C.Y.Y.; methodology, T.B.Y.C., I.M.D.C.C and A.C.Y.Y.; software, T.B.Y.C. and I.M.D.C.C.; validation, T.B.Y.C. and I.M.D.C.C.; formal analysis, T.B.Y.C., I.M.D.C.C. and W.Y.; resources, S.C.P.C., Q.N.C., J.Z. and G.H.Y.; data curation, T.B.Y.C. and I.M.D.C.C.; writing-original draft preparation, T.B.Y.C., I.M.D.C.C. and A.C.Y.Y.; writing-review and editing, A.C.Y.Y. and Q.N.C.; visualization, T.B.Y.C. and I.M.D.C.C.; supervision, A.C.Y.Y. and G.H.Y.; project administration, A.C.Y.Y. and G.H.Y.; funding acquisition, G.H.Y. All authors have read and agreed to the published version of the manuscript.

Funding: This research was funded by the Australian Research Council (ARC Industrial Training Transformation Centre, grant number: IC170100032) and the Australian Government Research Training Program Scholarship. All financial and technical supports are greatly appreciated.

Institutional Review Board Statement: Not applicable.

Informed Consent Statement: Not applicable. 
Data Availability Statement: The data presented in this study are not available from the authors.

Conflicts of Interest: The authors declare no conflict of interest.

\section{Nomenclature}

A Exponential factor

a Acceleration

$b_{n u c}^{*} \quad$ Normalised radical nuclei concentration

$\mathrm{c}_{\mathrm{i}} \quad$ Mass fraction

$C_{w} \quad$ WALE model constant

D Diffusivity

$E_{a} \quad$ Activation energy

$E_{\text {system }} \quad$ System energy

$E_{\text {bond }} \quad$ Bond energy

$E_{\text {over }} \quad$ Over-coordinated atom energy

$E_{\text {under }} \quad$ Under-coordinated atom energy

$E_{\text {val }} \quad$ Valence angle term

$E_{\text {pen }} \quad$ Penalty energy

$E_{\text {tors }} \quad$ Torsion energy

$E_{c o n j} \quad$ Conjugation effects to molecular energy

$E_{\text {vdWaals }}$ Nonbonded van der Waals interaction

$E_{\text {Coulomb }}$ Coulomb interaction

$\mathrm{F} \quad$ Instantaneous force

$\nabla f \quad$ Mixture fraction variance

g Gravity

$\mathrm{H} \quad$ Enthalpy

$H_{R} \quad$ Heat of reaction

$h_{s_{i}} \quad$ Heat of formation

$\bar{I}_{j} \quad$ Radiation intensities

K Thermal conductivity

$\bar{k}_{a} \quad$ Summation of the gas absorption coefficient

$L_{S} \quad$ Mixing length for sub-grid scales

$M_{\text {soot }} \quad$ Soot mass concentration

m Mass

$\dot{m}_{f u e l} \quad$ Fuel released at material surface

$N_{\text {soot }} \quad$ Number density of soot particles

$\mathrm{n}_{\mathrm{i}} \quad$ Reaction order of the reaction

$\mathrm{P} \quad$ Pressure

Q Heat released by the fluid combustion

$\dot{Q}_{p}^{\prime \prime} \quad$ Net heat gain due to chemical reactions during pyrolysis

$\dot{Q}_{r}^{\prime \prime} \quad$ Net heat gain due to chemical reactions via radiation absorption

$q_{r} \quad$ Flux equation of thermal radiation

$R \quad$ Gas constant

$R_{i} \quad$ Pyrolysis reaction rates

$S_{i j}^{d} \quad$ Rate-of-strain tensor

$T \quad$ Absolute temperature

Ts Solid fuel temperature

$t$ time

$\mathrm{u} \quad$ velocity

$\chi \quad$ Scalar dissipation

$\mathrm{X}$ Instantaneous particle position

$\mathrm{Y}_{\text {soot }} \quad$ Mass fraction of soot

$\mathrm{Z} \quad$ Elemental mass fraction

$\rho \quad$ Density

$\tau_{i j}^{s g s} \quad$ Subgrid-scale stresses

$\mu_{t} \quad$ Turbulent viscosity

$\kappa_{d} \quad$ Von Kármán constant 


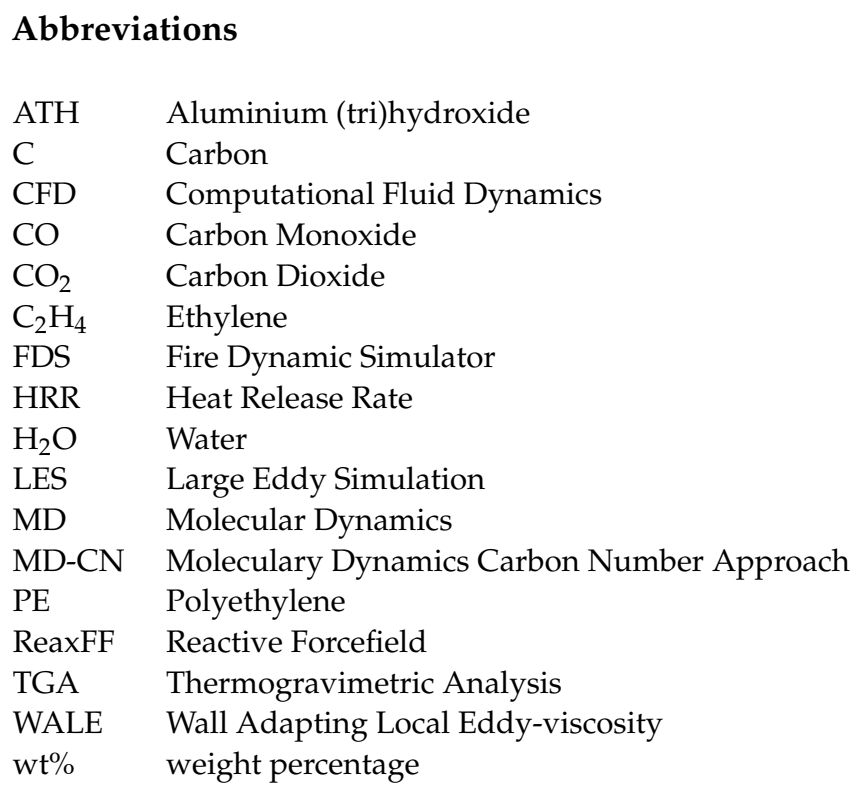

\section{References}

1. Evegren, F.; Hertzberg, T. Fire safety regulations and performance of fibre-reinforced polymer composite ship structures. Proc. Inst. Mech. Eng. Part M J. Eng. Marit. Environ. 2017, 231, 46-56. [CrossRef]

2. Morgan, A.B.; Gilman, J.W. An overview of flame retardancy of polymeric materials: Application, technology, and future directions. Fire Mater. 2013, 37, 259-279. [CrossRef]

3. Yuen, A.C.Y.; Chen, T.B.Y.; Yeoh, G.H.; Yang, W.; Cheung, S.C.-P.; Cook, M.; Yu, B.; Chan, Q.N.; Yip, H.L. Establishing pyrolysis kinetics for the modelling of the flammability and burning characteristics of solid combustible materials. J. Fire Sci. 2018, 36, 494-517. [CrossRef]

4. Yuen, A.C.Y.; Chen, T.B.Y.; Wang, C.; Wei, W.; Kabir, I.; Vargas, J.B.; Chan, Q.N.; Kook, S.; Yeoh, G.H. Utilising genetic algorithm to optimise pyrolysis kinetics for fire modelling and characterisation of chitosan/graphene oxide polyurethane composites. Compos. Part B Eng. 2020, 182, 107619. [CrossRef]

5. Mallet, V.; Keyes, D.E.; Fendell, F.E. Modeling wildland fire propagation with level set methods. Comput. Math. Appl. 2009, 57, 1089-1101. [CrossRef]

6. Rochoux, M.C.; Delmotte, B.; Cuenot, B.; Ricci, S.; Trouvé, A. Regional-scale simulations of wildland fire spread informed by real-time flame front observations. Proc. Combust. Inst. 2013, 34, 2641-2647. [CrossRef]

7. Chen, T.B.Y.; Yuen, A.C.Y.; Yeoh, G.H.; Timchenko, V.; Cheung, S.C.P.; Chan, Q.N.; Yang, W.; Lu, H. Numerical study of fire spread using the level-set method with large eddy simulation incorporating detailed chemical kinetics gas-phase combustion model. J. Comput. Sci. 2018, 24, 8-23. [CrossRef]

8. McGrattan, K.B.; McDermott, R.J.; Weinschenk, C.G.; Forney, G.P. Fire Dynamics Simulator Technical Reference Guide; National Institute of Standards and Technology: Gaithersburg, MD, USA, 2017.

9. Ding, Y.; Wang, C.; Lu, S. Modeling the pyrolysis of wet wood using FireFOAM. Energy Convers. Manag. 2015, 98, 500-506. [CrossRef]

10. Yuen, R.K.K.; Yeoh, G.H.; de Vahl Davis, G.; Leonardi, E. Modelling the pyrolysis of wet wood-I. Three-dimensional formulation and analysis. Int. J. Heat Mass Transf. 2007, 50, 4371-4386. [CrossRef]

11. Chen, T.B.Y.; Yuen, A.C.Y.; Wang, C.; Yeoh, G.H.; Timchenko, V.; Cheung, S.C.P.; Chan, Q.N.; Yang, W. Predicting the fire spread rate of a sloped pine needle board utilizing pyrolysis modelling with detailed gas-phase combustion. Int. J. Heat Mass Transf. 2018, 125, 310-322. [CrossRef]

12. Rein, G.; Lautenberger, C.; Fernandez-Pello, A.C.; Torero, J.L.; Urban, D.L. Application of genetic algorithms and thermogravimetry to determine the kinetics of polyurethane foam in smoldering combustion. Combust. Flame 2006, 146, 95-108 [CrossRef]

13. Mishra, G.; Kumar, J.; Bhaskar, T. Kinetic studies on the pyrolysis of pinewood. Bioresour. Technol. 2015, 182, 282-288. [CrossRef] [PubMed]

14. Ma, Z.; Chen, D.; Gu, J.; Bao, B.; Zhang, Q. Determination of pyrolysis characteristics and kinetics of palm kernel shell using TGA-FTIR and model-free integral methods. Energy Convers. Manag. 2015, 89, 251-259. [CrossRef]

15. Yang, H.; Wang, X.; Yuan, H.; Song, L.; Hu, Y.; Yuen, R.K.K. Fire performance and mechanical properties of phenolic foams modified by phosphorus-containing polyethers. J. Polym. Res. 2012, 19, 9831. [CrossRef]

16. Zhao, Q.; Zhang, B.; Quan, H.; Yam, R.C.M.; Yuen, R.K.K.; Li, R.K.Y. Flame retardancy of rice husk-filled high-density polyethylene ecocomposites. Compos. Sci. Technol. 2009, 69, 2675-2681. [CrossRef] 
17. Yuen, A.C.Y.; Chen, T.B.Y.; Lin, B.; Yang, W.; Kabir, I.I.; De Cachinho Cordeiro, I.M.; Whitten, A.E.; Mata, J.; Yu, B.; Lu, H.-D.; et al. Study of structure morphology and layer thickness of $\mathrm{Ti}_{3} \mathrm{C}_{2}$ MXene with Small-Angle Neutron Scattering (SANS). Compos. Part $C$ Open Access 2021, 5, 100155. [CrossRef]

18. Nguyen, Q.T.; Tran, P.; Ngo, T.D.; Tran, P.A.; Mendis, P. Experimental and computational investigations on fire resistance of GFRP composite for building façade. Compos. Part B Eng. 2014, 62, 218-229. [CrossRef]

19. Dutta, S.; Kim, N.K.; Das, R.; Bhattacharyya, D. Effects of sample orientation on the fire reaction properties of natural fibre composites. Compos. Part B Eng. 2019, 157, 195-206. [CrossRef]

20. Lin, B.; Yuen, A.C.Y.; Chen, T.B.Y.; Yu, B.; Yang, W.; Zhang, J.; Yao, Y.; Wu, S.; Wang, C.H.; Yeoh, G.H. Experimental and numerical perspective on the fire performance of MXene/Chitosan/Phytic acid coated flexible polyurethane foam. Sci. Rep. 2021, 11, 4684. [CrossRef]

21. Di Martino, G.D.; Carmicino, C.; Mungiguerra, S.; Savino, R. The Application of Computational Thermo-Fluid-Dynamics to the Simulation of Hybrid Rocket Internal Ballistics with Classical or Liquefying Fuels: A Review. Aerospace 2019, 6, 56. [CrossRef]

22. Tyurenkova, V.; Smirnova, M.J. Material combustion in oxidant flows: Self-similar solutions. Acta Astronaut. 2016, 120, 129-137. [CrossRef]

23. Betelin, V.; Kushnirenko, A.; Smirnov, N.; Nikitin, V.; Tyurenkova, V.; Stamov, L. Numerical investigations of hybrid rocket engines. Acta Astronaut. 2018, 144, 363-370. [CrossRef]

24. Tyurenkova, V.V.; Stamov, L.I. Flame propagation in weightlessness above the burning surface of material. Acta Astronaut. 2019, 159, 342-348. [CrossRef]

25. Kushnirenko, A.; Stamov, L.; Tyurenkova, V.; Smirnova, M.; Mikhalchenko, E. Three-dimensional numerical modeling of a rocket engine with solid fuel. Acta Astronaut. 2021, 181, 544-551. [CrossRef]

26. Yuen, A.C.Y.; Chen, T.B.Y.; Li, A.; De Cachinho Cordeiro, I.M.; Liu, L.; Liu, H.; Lo, A.L.P.; Chan, Q.N.; Yeoh, G.H. Evaluating the fire risk associated with cladding panels: An overview of fire incidents, policies, and future perspective in fire standards. Fire Mater. 2021, 45, 663-689. [CrossRef]

27. Ciottoli, P.P.; Malpica Galassi, R.; Lapenna, P.E.; Leccese, G.; Bianchi, D.; Nasuti, F.; Creta, F.; Valorani, M. CSP-based chemical kinetics mechanisms simplification strategy for non-premixed combustion: An application to hybrid rocket propulsion. Combust. Flame 2017, 186, 83-93. [CrossRef]

28. Van Duin, A.C.; Dasgupta, S.; Lorant, F.; Goddard, W.A. ReaxFF: A reactive force field for hydrocarbons. J. Phys. Chem. A 2001, 105, 9396-9409. [CrossRef]

29. Chen, T.B.Y.; Yuen, A.C.Y.; Lin, B.; Liu, L.; Lo, A.; Chan, Q.N.; Zhang, J.; Cheung, S.C.P.; Yeoh, G.H. Characterisation of pyrolysis kinetics and detailed gas species formations of engineering polymers via reactive molecular dynamics (ReaxFF). J. Anal. Appl. Pyrolysis 2020, 153, 104931. [CrossRef]

30. Vaari, J.; Paajanen, A. Evaluation of the reactive molecular dynamics method for Research on flame retardants: ATH-filled polyethylene. Comput. Mater. Sci. 2018, 153, 103-112. [CrossRef]

31. Rahmani, F.; Mahdavi, M.; Nouranian, S.; Al-Ostaz, A. Confinement effects on the thermal stability of poly (ethylene oxide)/graphene nanocomposites: A reactive molecular dynamics simulation study. J. Polym. Sci. Part B Polym. Phys. 2017, 55, 1026-1035. [CrossRef]

32. Lan, Y.; Li, D.; Yang, R.; Liang, W.; Zhou, L.; Chen, Z. Computer simulation study on the compatibility of cyclotriphosphazene containing aminopropylsilicone functional group in flame retarded polypropylene/ammonium polyphosphate composites. Compos. Sci. Technol. 2013, 88, 9-15. [CrossRef]

33. Stoliarov, S.I.; Westmoreland, P.R.; Nyden, M.R.; Forney, G.P. A reactive molecular dynamics model of thermal decomposition in polymers: I. Poly(methyl methacrylate). Polymer 2003, 44, 883-894. [CrossRef]

34. Stoliarov, S.I.; Lyon, R.E.; Nyden, M.R. A reactive molecular dynamics model of thermal decomposition in polymers. II. Polyisobutylene. Polymer 2004, 45, 8613-8621. [CrossRef]

35. Liu, X.; Li, X.; Liu, J.; Wang, Z.; Kong, B.; Gong, X.; Yang, X.; Lin, W.; Guo, L. Study of high density polyethylene (HDPE) pyrolysis with reactive molecular dynamics. Polym. Degrad. Stab. 2014, 104, 62-70. [CrossRef]

36. Wan, Y.; Yu, S.; Jiang, S.; Pei, Q.; Xu, S.; Cao, W.; Liu, X.; Lan, Y. Microscopic pyrolysis mechanism on the octyphenylsiloxane flame retarded polycarbonate by reactive molecular dynamics. J. Anal. Appl. Pyrolysis 2021, 158, 105274. [CrossRef]

37. Li, G.-Y.; Li, A.-Q.; Zhang, H.; Wang, J.-P.; Chen, S.-Y.; Liang, Y.-H. Theoretical study of the CO formation mechanism in the CO2 gasification of lignite. Fuel 2018, 211, 353-362. [CrossRef]

38. Xu, F.; Liu, H.; Wang, Q.; Pan, S.; Zhao, D.; Liu, Q.; Liu, Y. ReaxFF-based molecular dynamics simulation of the initial pyrolysis mechanism of lignite. Fuel Process. Technol. 2019, 195, 106147. [CrossRef]

39. Hong, D.; Li, P.; Si, T.; Guo, X.J.E. ReaxFF simulations of the synergistic effect mechanisms during co-pyrolysis of coal and polyethylene/polystyrene. Energy 2021, 218, 119553. [CrossRef]

40. Fletcher, T.H.; Kerstein, A.R.; Pugmire, R.J.; Solum, M.S.; Grant, D.M. Chemical percolation model for devolatilization. 3. Direct use of carbon-13 NMR data to predict effects of coal type. Energy Fuels 1992, 6, 414-431. [CrossRef]

41. Sinfrônio, F.S.M.; Santos, J.C.O.; Pereira, L.G.; Souza, A.G.; Conceiçăo, M.; Fernandes, V.J., Jr.; Fonseca, V.M. calorimetry, Kinetic of thermal degradation of low-density and high-density polyethylene by non-isothermal thermogravimetry. J. Therm. Anal. Calorim. 2005, 79, 393-399. [CrossRef] 
42. DiNenno, P.J.; Drysdale, D.; Beyler, C.L.; Walton, D.W. SFPE Handbook of Fire Protection Engineering, 3rd ed.; National Fire Protection Association: Quincy, MA, USA, 2002.

43. Plimpton, S. Fast Parallel Algorithms for Short-Range Molecular Dynamics. J. Comput. Phys. 1995, 117, 1-19. [CrossRef]

44. Aktulga, H.M.; Fogarty, J.C.; Pandit, S.A.; Grama, A.Y. Parallel reactive molecular dynamics: Numerical methods and algorithmic techniques. Parallel Comput. 2012, 38, 245-259. [CrossRef]

45. Hong, S.; Van Duin, A.C. Atomistic-scale analysis of carbon coating and its effect on the oxidation of aluminum nanoparticles by ReaxFF-molecular dynamics simulations. J. Phys. Chem. C 2016, 120, 9464-9474. [CrossRef]

46. Martínez, L.; Andrade, R.; Birgin, E.G.; Martínez, J.M. PACKMOL: A package for building initial configurations for molecular dynamics simulations. J. Comput. Chem. 2009, 30, 2157-2164. [CrossRef]

47. Hoover, W.G. Canonical dynamics: Equilibrium phase-space distributions. Phys. Rev. A 1985, 31, 1695-1697. [CrossRef]

48. Salmon, E.; van Duin, A.C.; Lorant, F.; Marquaire, P.-M.; Goddard, W.A., III. Early maturation processes in coal. Part 2: Reactive dynamics simulations using the ReaxFF reactive force field on Morwell Brown coal structures. Org. Geochem. 2009, 40, 1195-1209. [CrossRef]

49. Salmon, E.; van Duin, A.C.; Lorant, F.; Marquaire, P.-M.; Goddard, W.A., III. Thermal decomposition process in algaenan of Botryococcus braunii race L. Part 2: Molecular dynamics simulations using the ReaxFF reactive force field. Org. Geochem. 2009, 40, 416-427. [CrossRef]

50. Chenoweth, K.; Cheung, S.; Van Duin, A.C.; Goddard, W.A.; Kober, E.M. Simulations on the thermal decomposition of a poly (dimethylsiloxane) polymer using the ReaxFF reactive force field. J. Am. Chem. Soc. 2005, 127, 7192-7202. [CrossRef]

51. Diao, Z.; Zhao, Y.; Chen, B.; Duan, C.; Song, S. ReaxFF reactive force field for molecular dynamics simulations of epoxy resin thermal decomposition with model compound. J. Anal. Appl. Pyrolysis 2013, 104, 618-624. [CrossRef]

52. Risberg, D.; Risberg, M.; Westerlund, L. CFD modelling of radiators in buildings with user-defined wall functions. Appl. Therm. Eng. 2016, 94, 266-273. [CrossRef]

53. De Cachinho Cordeiro, I.M.; Liu, H.; Yuen, A.C.Y.; Chen, T.B.Y.; Li, A.; Cao, R.F.; Yeoh, G.H. Numerical investigation of expandable graphite suppression on metal-based fire. Heat Mass Transf. 2021. [CrossRef]

54. De Cachinho Cordeiro, I.M.; Liu, H.; Yuen, A.C.Y.; Chen, T.B.Y.; Li, A.; Yeoh, G.H. Numerical assessment of LES subgrid-scale turbulence models for expandable particles in fire suppression. Exp. Comput. Multiph. Flow 2021. [CrossRef]

55. e Silva, V.B.R.; Cardoso, J. Computational Fluid Dynamics Applied to Waste-to-Energy Processes: A Hands-on Approach; ButterworthHeinemann: Cambridge, MA, USA, 2020.

56. Mochizuki, H. Verification of neutronics and thermal-hydraulics coupling method for FLUENT code using the MSRE pump startup, trip data. Nucl. Eng. Des. 2021, 378, 111191. [CrossRef]

57. Brookes, S.J.; Moss, J.B. Predictions of soot and thermal radiation properties in confined turbulent jet diffusion flames. Combust. Flame 1999, 116, 486-503. [CrossRef]

58. Yuen, A.C.Y.; Yeoh, G.H. Numerical simulation of an enclosure fire in a large test hall. Comput. Therm. Sci. $2013,5,459-471$. [CrossRef]

59. Yuen, A.C.Y.; Yeoh, G.H.; Yuen, R.K.K.; Chen, T. Numerical Simulation of a Ceiling Jet Fire in a Large Compartment. Procedia Eng. 2013, 52, 3-12.

60. Nicoud, F.; Ducros, F. Subgrid-Scale Stress Modelling Based on the Square of the Velocity Gradient Tensor. Flow Turbul. Combust. 1999, 62, 183-200. [CrossRef]

61. Smagorinsky, J. General circulation experiments with the primitive equations, i. the basic experiment. Mon. Weather Rev. 1963, 91, 99-164. [CrossRef]

62. Yuen, A.C.Y.; Yeoh, G.H.; Timchenko, V.; Cheung, S.C.P.; Chen, T. Study of three LES subgrid-scale turbulence models for predictions of heat and mass transfer in large-scale compartment fires. Numer. Heat Transf. Part A 2016, 69, 1223-1241. [CrossRef]

63. Chen, Q.; Chen, T.B.Y.; Yuen, A.C.Y.; Wang, C.; Chan, Q.N.; Yeoh, G.H. Investigation of door width towards flame tilting behaviours and combustion species in compartment fire scenarios using large eddy simulation. Int. J. Heat Mass Transf. 2020, 150, 119373. [CrossRef]

64. Smith, G.P.; Golden, D.M.; Frenklach, M.; Moriarty, N.W.; Eiteneer, B.; Goldenberg, M.; Bowman, C.T.; Hanson, R.K.; Song, S.; Gardiner, W.C., Jr.; et al. GRI-Mech, Version 3.0. 2000. Available online: http:/ / www.me.berkeley.edu/gri_mech/ (accessed on 11 June 2021).

65. Kee, R.J.; Rupley, F.M.; Miller, J.A.; Coltrin, M.E.; Grcar, J.F.; Meeks, E. CHEMKIN Collection, Release 3.6; Reaction Design, Inc.: San Diego, CA, USA, 2000.

66. Yuen, A.C.Y.; Yeoh, G.H.; Timchenko, V.; Chen, T.B.Y.; Chan, Q.N.; Wang, C.; Li, D.D. Comparison of detailed soot formation models for sooty and non-sooty flames in an under-ventilated ISO room. Int. J. Heat Mass Transf. 2017, 115, 717-729. [CrossRef]

67. Yuen, A.C.Y.; Yeoh, G.H.; Timchenko, V.; Cheung, S.C.P.; Barber, T.J. Importance of detailed chemical kinetics on combustion and soot modelling of ventilated and under-ventilated fires in compartment. Int. J. Heat Mass Transf. 2016, 96, 171-188. [CrossRef]

68. Jamaluddin, A.S.; Smith, P.J. Predicting Radiative Transfer in Rectangular Enclosures Using the Discrete Ordinates Method. Combust. Sci. Technol. 1988, 59, 321-340. [CrossRef]

69. Beer, J.M.; Foster, P.J.; Siddall, R.G. Calculation Methods of Radiation Heat Transfer; HFTS Design Report No. 22; AEA Technology: Burlington, MA, USA, 1971.

70. Kent, J.; Honnery, D. A soot formation rate map for a laminar ethylene diffusion flame. Combust. Flame 1990, 79, 287-298. [CrossRef] 